\title{
Who Do I (Dis)Trust and Monitor for Ethical Misconduct? Status, Power, and the Structural Paradox
}

\author{
Kelly $\operatorname{Raz}^{1} \mathbb{1} \cdot$ Alison R. Fragale ${ }^{2} \cdot$ Liat Levontin $^{3}$
}

Received: 6 October 2020 / Accepted: 30 October 2021 / Published online: 30 November 2021

(C) The Author(s), under exclusive licence to Springer Nature B.V. 2021

\begin{abstract}
A wealth of research documents the critical role of trust for social exchange and cooperative behavior. The ability to inspire trust in others can often be elusive, and distrust can have adverse interpersonal and ethical consequences. Drawing from the literature on social hierarchy and interpersonal judgments, the current research explores the predictive role of a structural paradox between high power and low status in identifying the actors most likely to be distrusted and monitored for ethical misconduct. Across four studies and an internal meta-analysis, we found that the structural paradox was associated with distrust-related judgments and behaviors. In Study 1, high power-low status actors were judged as less trustworthy. In Studies 2 and 3, high power-low status actors were sent less money in a trust game, an effect fully mediated by feelings of dislike. Study 4 revealed that high power-low status actors were more likely to be monitored for cheating, an effect partially mediated by trust judgments. These findings contribute to business ethics research by identifying the structural paradox of high power-low status as a salient contextual influence impacting observers' distrust and monitoring dynamics. Implications for reducing observers' level of distrust of high power-low status actors are discussed.
\end{abstract}

Keywords Distrust $\cdot$ Status $\cdot$ Hierarchy $\cdot$ Power $\cdot$ Monitoring behaviors

\section{Introduction}

The benefits of interpersonal trust as a core ingredient for effective social interactions and exchange is well recognized (Cook et al., 2005; Long \& Sitkin, 2018). Nowhere is this more evident than in today's climate of social media, COVID-19 era, and more complex commercial and political institutions, where interactions between and among

Kelly Raz

razkel@post.bgu.ac.il

Alison R. Fragale

afragale@unc.edu

Liat Levontin

levontin@ie.technion.ac.il

1 Guilford Glazer Faculty of Business and Management, BenGurion University of the Negev, P.O.B. 653, Beer-Sheva, Israel

2 Kenan-Flagler Business School, University of North Carolina at Chapel Hill, McColl 4734, CB 3490, Chapel Hill, NC, USA

3 Faculty of Industrial Engineering and Management, Technion, Israel Institute of Technology, Haifa, Israel individuals are increasingly becoming online and depersonalized (Etzioni, 2019; Levine, 2019). To name a few of the many examples in daily life: Crowdfunding investors decide to trust unknown entrepreneurs and founders; hiring managers decide to trust or distrust online applicants' claims for intangible skills; and digital media consumers must decide whose journalistic and political opinions to trust, or possibly more importantly, who to distrust.

Despite its many benefits, the ability to inspire trust in others is often elusive. For example, a recent poll by the Pew Research Center found that the majority of Americans distrust their elected officials and business leaders (Pew Research Center, 2019). Failure to inspire trust carries important implications for business ethics research. That is, distrust has been associated with heightened deception and suspicion (Deutsch, 1958; Kramer, 1999), defensiveness and sabotage (Zand, 1972), a lack of cooperation (Cho, 2006), counterproductive behaviors (Colquitt et al., 2007), animosity (Chambers \& Melnyk, 2006), intergroup conflict (Bijlsma-Frankema et al., 2015), tax evasion (Alasfour, 2019), and unethical organizational practices (De Cremer et al., 2010). Given these adverse consequences, it seems 
critical that researchers understand the factors that impact observers' distrust.

When distrust is not based on direct personal interactions, trust judgments must be based on the information that is available such as incidental information that is encountered in the course of one's work or social environment (Kramer, 1999; Mayer et al., 1995; Rousseau et al., 1998; Schilke \& Huang, 2018). Past research has shown that people attend to a wide range of target-specific characteristics to detect whether others can be trusted such as: nonverbal behaviors, facial appearance, self-control, reputation, concern for social issues, and shared group membership (Balliet et al., 2014; DeSteno et al., 2012; Righetti \& Finkenauer, 2011; Tanis \& Postmes, 2005; Tinsley et al., 2002; Willis \& Todorov, 2006; Zlatev, 2019). Recent work has begun focusing on social-contextual features and has identified an actor's place in a social hierarchy - their level of power and status-as especially pertinent to our understanding of interpersonal trust development. Research in this tradition has largely demonstrated the isolated effect of having power-control over valued resources - or status - the level of regard and respect granted by others- on one's own trust-related behavior (Lount \& Pettit, 2012; Magee \& Galinsky, 2008; Schilke et al., 2015). For example, an actor's possession of status increases their trust in others (Lount \& Pettit, 2012), while an actor's possession of power decreases their trust in others (Brion et al., 2019; Mooijman et al., 2019; Schilke et al., 2015). From the perspective of third-party observers, high status actors are trusted more than low status actors (Blue et al., 2019).

Despite this increased attention, the interactive effect of an actor's power and status on observers' distrust has remained an open question. This is an important oversight because one particular distribution of power and status-high power accompanied by low status-is not only prevalent in many societal and work contexts but has been associated with more negative judgments and behavioral outcomes, including demeaning behavior, conflictual interactions, and injustice (Anicich et al., 2015; Blader \& Chen, 2012; Fast et al., 2012; Fragale et al., 2011). A closer examination of the cues associated with high power-low status actors, therefore, may provide insight into which actors are most likely to be distrusted.

In this paper, we contribute to interdisciplinary research between psychology and business ethics (Islam, 2020) to identify cues likely to lead to distrust. We build on the existing literatures of social hierarchy and interpersonal judgments to explore how an actor's structural position in a social hierarchy, determined by their level of power and status, affects the distrust they receive from others. Using four experimental studies, we show how a paradox in an actor's hierarchical position-their high power-low status position-can influence the distrust and related behavioral consequences they will experience from third-party observers.

\section{Background and Hypotheses}

\section{The Structural Paradox}

One critical factor affecting trust is the existing social hierarchy and its underlying structural mechanisms of power and status. Hierarchy, whether formal or informal, is defined as a stratified social structure that rank orders actors along valued social dimensions; two of the most fundamental dimensions underlying the hierarchical sorting process are power and status (Magee \& Galinsky, 2008; Mannix \& Sauer, 2006). Power is the result of one's ability to control valued resources, whereas status is respect and regard that is socially awarded on the basis of others' positive evaluations (Anderson et al., 2001; Blader \& Chen, 2012; Magee \& Galinsky, 2008). Status is often conferred to those who are seen as contributing the most to a group's success and functioning and signals an ability to set aside personal agendas and contribute to group goals (Anderson et al., 2015; Blader $\&$ Chen, 2012). High status signals that an actor's interests are aligned with the group and its collective members, which is the essence of trust. Indeed, research has shown that people trust high status actors more than low status ones (Blue et al., 2019).

Research on power has traditionally focused on its role in an actor's own judgments and behavior. For example, power can activate approach-related behaviors, heighten mating expectations, increase racial prejudice and the objectification of others, and reduce compassion (Gruenfeld et al., 2008; Guinote et al., 2010; Guinote, 2017; Keltner et al., 2003; Kuntsman \& Maner, 2011; van Kleef et al., 2008). On the other hand, a lack of power is associated with negative affect, vigilance, and inhibition but not when the actor also possesses status (Deng et al., 2018; Keltner et al., 2003).

Moving beyond an actor's own judgments and behavior, research examining the social evaluation of another's power has found that it is subject to a number of contextual factors. For instance, power can threaten and convey fear when it is used to intimidate and coerce others (Cheng et al., 2013). Moreover, the powerful are subject to negative stereotypes when they lack status (Fragale et al., 2011). Within a power relationship, (dis)trust is predicated on the powerless' expectations of how the powerful will exercise their power. In particular, distrust reflects observers' perceptions that their interests and the interests of those with power are in conflict (Lewicki et al., 1998; Massey et al., 1997; Schul et al., 2008). We contend that this is signaled by the powerholder's level of status; high status suggests that their power is legitimate 
and trustworthy (van der Toorn et al., 2011). Thus, it is an actor's level of status (i.e., high or low) combined with their level of power that is expected to determine the (dis) trust they will experience in a relationship.

Because political, social, or organizational systems of hierarchy can and do give rise to unequal levels of power and status among and within individuals, power and status are not always aligned (Anicich et al., 2015; Fragale et al., 2011). This can happen, for instance, when an actor's level of power (i.e., control over valued resources) exceeds the level of regard and respect granted by others (i.e., status). A politician may control important resources but may not be seen as well respected by outside observers (i.e., the other parties' voters or politicians from other governments). A reimbursement clerk may have power over unpaid employees (i.e., money), but little status in their eyes (Anicich et al., 2016). Indeed, any authority figure, who has power by definition, is trusted less when they lack legitimacy (i.e., perceived low status; van der Toorn et al., 2011).

When this happens, a contradiction is introduced between observers' expectations of what is legitimate and appropriate, and an actor's access to valued resources. In particular, we define a structural paradox as a misalignment between the two structural bases of hierarchy: power and status. We propose that a structural paradox, between high power and low status, leads to observers' distrust directed toward an actor's intentions and actions beyond the distrust associated with the isolated effect of an actor's status. This proposition is based on the idea that people expect those who wield power to also possess status and experience an adverse reaction when these expectations are not met. We draw on the meaning maintenance model (Heine et al., 2006; Proulx et al., 2012), which argues that people utilize expected relationships to organize and make sense of their world. Violations to expected relationships can be perceived as threatening and can motivate compensatory strategies to maintain a sense of meaning. For example, blaming the victim of a tragedy can help preserve beliefs in a just world (Proulx \& Heine, 2010; Proulx et al., 2012). In the context of social hierarchy, power and status are often conceptualized as complementary and selfreinforcing as power is often entrusted to respect others, and status often yields power (Fiske, 2010; Magee \& Galinsky, 2008). Given that distrust is typically experienced when people sense that a situation is amiss and unexpected (Schul et al., 2008), an unknown actor's high power-low status may violate third-party observers' expected associations between status and power. We contend that people expect actors with low status to have low power. Thus, when low status actors violate this expectation by possessing power, we suggest that observers will experience a status violation triggering an adverse reaction and distrust.

\section{(Dis)Trust Behavior and Judgments}

Distrust is expected to be evidenced in negative trust judgments, reduced trusting behavior, and increased distrusting behavior. Trust is defined as the willingness to be vulnerable to another's actions (Kramer, 1999; Mayer et al., 1995; Rousseau et al., 1998); distrust is conversely defined as the unwillingness to risk vulnerability to another's actions and has been conceptualized as both the opposite end of the trust continuum and as a related yet distinct construct from trust (Lewicki et al., 1998; Saunders et al., 2014; Schoorman et al., 2007). In both conceptualizations, distrust, unlike trust, reflects observers' perceptions that another's intentions and one's own interests are in conflict (Lewicki et al., 1998; Schul et al., 2008). When this occurs, observers focus on the potential for negative outcomes and react with fear or unease regarding another's motives, intentions, and potential actions (Kramer, 1999). For example, there is a tendency to be on guard and to assume deception by distrusted others (Schul et al., 2008). In this paper, we focus on depersonalized distrust which extends beyond the boundaries of faceto-face interactions by incorporating strangers or third-party observers that have limited social and contextual information and may never physically meet (Dunning et al., 2014; Stolle, 2002).

Trust judgments represent the expectations that observers have of another's character and ability and differ from observers' actual trust behaviors (Colquitt et al., 2007). That is, studies have found that people's trust judgments are more negative than is exhibited by their actual trust behavior, suggesting that the two are correlated but are not the same (Dunning et al., 2014; Fetchenhauer \& Dunning, 2009). Mayer et al. (1995) identified three distinct qualities of a trustee that inform trust judgments: ability, benevolence, and integrity. Ability is defined as the observer's assessment of the skills and competencies of the trustee; benevolence inspires the belief that the trustee wants to do right for the trustor; and integrity reflects judgments of the trustee's adherence to principles the trustor finds acceptable. These judgments of trustworthiness are considered antecedents for fostering both trust and distrust behaviors (Colquitt et al., 2007; Lewicki et al., 1998; Mayer \& Davis, 1999; Mayer et al., 1995).

We know from past research that high status individuals are trusted more than low status ones (Blue et al., 2019). We also know that high status individuals are considered warm regardless of how much power they possess, but low status individuals are considered cold when they also possess high power (Blue et al., 2019; Fiske et al., 2007; Fragale et al., 2011). Building on these findings, we argue that power moderates the effect of status on observers' depersonalized distrust. Specifically, when status is low, we expect that variations in power to have an effect on observers' level of distrust. That is, we expect that observers will distrust high 
power-low status actors more than low power-low status actors because of a violation in expectation that low status will be accompanied by low power. Although low status cues signal a lack of respect, admiration, and legitimacy and are likely to be viewed in a negative light, we suggest that the violation of status expectations introduced by the structural paradox is more impactful, and thus, more salient in observers' minds. Thus, we expect higher distrust of low status actors, if they are also perceived as high power rather than low power.

However, we expect when status is high, variation in another's power will not affect observers' level of distrust. Although the combination of low power and high status may also signal a violation of expectations between power and status, we still expect that observers will trust high status actors, with or without power, more than low status actors who possess power. This is because status is often conferred to those who are seen as contributing the most to a group's success and functioning (Anderson et al., 2015; Overbeck et al., 2005); thus, with or without power, high status should signal that the status holder is more trustworthy than low status actors and has used their talents and resources, including any power they have, to benefit others. Thus, we expect an adverse reaction and distrust from a violation of expectations between status and power when high power is accompanied by low status. Stated formally:

H1 Power will moderate the effect of status on observers' depersonalized distrust judgments and behavior such that high power-low status actors will experience more distrust than low power-low status actors (H1a), high power-high status actors (H1b), and low power-high status actor (H1c).

\section{Monitoring for Ethical Misconduct}

As the workplace takes on a virtual element and remote working arrangement become more prevalent, an increasing number of employees are being granted full autonomy over their work and time. Managers are increasingly relying on supervisory control mechanisms that control and monitor employee activities with the purpose of aligning employee goals with those of the organizations (Alge et al., 2004; Bernstein, 2017; Langfred, 2004; Langfred \& Rockmann, 2016). In particular, the absence of face-to-face interactions and supervision is likely to present organizations with unique ethics challenges such as the increased likelihood of intellectual property and data theft, breaches of confidentiality, as well as employee shirking of and misreporting hours (Treviño et al., 2014). Indeed, research has shown that people are more likely to deceive in remote and online environments (Levy, 2015; Naquin et al., 2010). Organizations, for their part, have begun to electronically monitor such things as employee internet, social media, and personal e-mail use
(Alder et al., 2008; Ball, 2010; Bernstein, 2017; Haesevoets et al., 2019; Schweitzer et al., 2018).

Monitoring behaviors have important interpersonal, managerial, and ethical implications (Martin \& Freeman, 2003). For example, workplace monitoring can be viewed as an infringement of employees' privacy which can hinder employee learning and creativity (Acquisti et al., 2015; Bernstein, 2017; Bhave et al., 2020; Thompson et al., 2009). One noteworthy outcome of monitoring is that the accusers of ethical misconduct are perceived as having high ethical standards when they accuse others (Kennedy \& Schweitzer, 2018). This suggests that ethical monitoring can be exploited for personal gain and, thus, has the potential to contribute to a climate of organizational mistreatment of employees (Graso et al., 2020; Kennedy \& Schweitzer, 2018). As remote workplace dynamics give monitoring a more tangible role, there is a need to know more about which actors are most vulnerable to be typecast as perpetrators of unethical behavior and the cues that trigger decisions to ethically monitor them. This is partly because ethical monitoring can be viewed as inherently unethical if actors are disproportionately targeted based on nothing aside from social-contextual information about their place in the hierarchy.

When observers' energy is directed toward monitoring another actor's behavior, it suggests that they are suspicious of the actor's motives (Schul et al., 2008). In remote workplace contexts, suspicion refers to uncertainty regarding whether actors have hidden and/or rival motives (Bobko et al., 2014; Sinaceur, 2010); distrust, on the other hand, refers to unambiguous negative judgments regarding another's intentions (Bobko et al., 2014; Fein, 1996; Sinaceur, 2010). Nevertheless, at its core, suspicion is based on a concern that another's motives are harmful (Bobko et al., 2014; Sinaceur, 2010). Thus, we suggest that actors who are distrusted will face greater suspicion and increased monitoring for ethical breaches. We propose that high power-low status actors are more likely to be monitored for ethical misconduct than all combinations of power and status because they are perceived to be less trustworthy. In particular, we predict that observers' trust judgments mediate the relationship between the structural paradox and monitoring another actor for unethical behavior. Stated formally:

H2 Power will moderate the effect of status on monitoring such that high power-low status actors will face greater monitoring for ethical misconduct than low power-low status actors ( $\mathrm{H} 2 \mathrm{a})$, high power-high status actors $(\mathrm{H} 2 \mathrm{~b})$, and low power-high status actors $(\mathrm{H} 2 \mathrm{c})$.

H3 Distrust judgments will mediate the moderating effect of power and status on monitoring such that high powerlow status actors will face greater monitoring for ethical misconduct. 
In this paper, we extend the literature in two ways. First, we demonstrate who is likely to be (dis)trusted based on indirect information hinting at their power and status in the observers' context. Second, we show that monitoring for ethical misconduct is partially influenced by this indirect information. In short, we expect cues of high power-low status to induce low trust judgments, which should mediate the effect of the structural paradox on behavioral consequences of distrust, one of which is the explicit monitoring of another's ethical behavior.

\section{The Present Investigation}

In four studies, we manipulate an actor's level of power and status in one relationship and test whether it will affect observers' (dis)trust in a new potential interaction partner. The use of experiments allowed us to causally investigate whether the structural paradox predicts third-party observers' depersonalized distrust. The first three studies tested our first hypothesis. Study 1 tested whether high power-low status actors are judged as less trustworthy by third-party observers than low power-low status (H1a), high power-high status (H1b), and low power-high status (H1c) actors. Studies 2 and 3 tested whether participants distrust a high powerlow status actor more than a low power-low status (H1a), high power-high status (H1b), and low power-high status (H1c) actor as indicated by their response to that person in a trust game, a behavioral indicator of trusting others to reciprocate resources (Berg et al., 1995; Lount \& Pettit, 2012).

Study 4 assessed $\mathrm{H} 2$ and $\mathrm{H} 3$ by testing the mediating role of trust judgments in predicting observers' monitoring behavior. Specifically, Study 4 examined whether observers would be more likely to monitor high power-low status actors than low power-low status (H2a), high power-high status $(\mathrm{H} 2 \mathrm{~b})$, and low power-high status $(\mathrm{H} 2 \mathrm{c})$ actors for cheating.

We end with an internal meta-analysis of the estimated effect of observers' distrust of high power-low status actors as compared across all combinations of status and power across Studies 1 through 4 . This analysis provides support for our hypotheses that high power-low status actors are distrusted more than actors with all power and status combinations.

\section{Study 1: Structural Paradox and Trust Judgments}

The purpose of Study 1 was to test whether an actor's level of power and status predicts observers' trust judgments. In line with our first hypothesis, we expected that participants would rate high power-low status actors as less trustworthy than actors with all combinations of power and status.

\section{Method}

\section{Participants}

We recruited participants via Amazon's Mechanical Turk (Mturk) with the goal of averaging 125 per group (i.e., four groups). MTurk has been found to be a highly reliable source and more demographically varied than undergraduate and other Internet samples (Buhrmester et al., 2011; Paolacci \& Chandler, 2014). All participants were screened with a onequestion check to verify that they were paying attention. If an individual failed the attention check, the individual was not counted as a study participant, leaving 467 participants (48\% females; $M_{\text {age }}=35, S D_{\text {age }}=11.47$ ) in the final sample. Posthoc power analysis (Faul et al., 2007) indicates $99 \%$ power with this sample size to detect a medium effect size for a MANOVA $\left(f=0.0625\right.$; medium effect, $0.25^{\wedge} 2, \alpha=0.05$ ). All data were analyzed after data collection concluded.

\section{Procedure}

Participants were informed that they would be participating in a test of a new platform to enable online workers to collaborate. Participants were randomly paired with a fictitious unknown partner in a 2 (status: high vs. low) $\times 2$ (power: high vs. low) between-subjects design and were given feedback about their partner from former teammates. The content of the feedback served to manipulate high and low levels of status and power and was adapted from Fragale et al. (2011) and Fast et al. (2012). Participants read, "Worker worked on a three-person team. Worker was (wasn't) in charge of how much bonus each person earned, so they had a lot of (very little) power in our group. At the same time, they were (weren't) very respected or regarded in our group-high (low) status, I would say."

As a manipulation check, participants rated how much status and power they thought their unknown partner had each on a single-item Likert scale $(1=$ not at all to $7=$ very much so). Next, participants rated their impression of their partner's trustworthiness using the four facets of Mayer and Davis's (1999) measure: ability, benevolence, integrity, and general trust. Items were adapted slightly to refer to workers on Mturk. Examples include: This worker is very capable of performing his/her job (ability, 5 items, $\alpha=0.95$ ); This worker would not knowingly do anything to hurt me (benevolence, 5 items, $\alpha=0.92$ ); I never have to wonder whether this worker will stick to his/her word (integrity, 6 items, $\alpha=0.90$ ); I would be comfortable giving this worker a task or problem, which was critical to me, even if I could not monitor his/her actions (general trust, 4 items, $\alpha=0.74$ ). Finally, participants responded to demographic items and were debriefed. 


\section{Results and Discussion}

\section{Manipulation Check}

Confirming that the status manipulation worked as expected $\left(F(1,465)=231.34, p<0.001, \eta_{\mathrm{p}}{ }^{2}=0.33\right)$, participants perceived that high status partners had more status $(M=4.98$, $S E=0.08)$ than low status partners $(M=3.27, S E=0.08$, $t(465)=15.21, p<0.001,95 \%$ CI $[1.49,1.93])$. The power manipulation also worked as expected $(F(1,465)=36.25$, $\left.p<0.001, \eta_{\mathrm{p}}{ }^{2}=0.07\right)$, participants perceived high power partners to have more power $(M=4.46, S E=0.08)$, than low power partners $(M=3.75, S E=0.08, t(465)=6.02$, $p<0.001,95 \%$ CI $[0.48,0.95])$.

\section{Trust Judgments}

Given the multiple dependent variables, a 2 (power: high vs. low) $\times 2$ (status: high vs. low) MANOVA on the four trust scales (i.e., general trust, benevolence, integrity, and ability) was conducted. We found significant main effects for both status (Wilk's $\lambda=0.58, F(4,463)=82.38, p<0.001$, $\eta_{\mathrm{p}}{ }^{2}=0.42$ ) and power (Wilk's $\lambda=0.93, F(4,463)=8.95$, $\left.p<0.001, \eta_{\mathrm{p}}^{2}=0.07\right)$. These results were qualified by a significant power $\times$ status interaction (Wilk's $\lambda=0.95, F(4$, $463)=6.46, p<0.001, \eta_{\mathrm{p}}{ }^{2}=0.05$ ).

Univariate analysis showed that the interaction of status and power was significant for three of the four trust judgements: general trust $\left[F(1,463)=8.53, p=0.004, \eta_{\mathrm{p}}{ }^{2}=0.01\right]$, benevolence $\left[F(1,463)=16.07, p<0.001, \eta_{\mathrm{p}}{ }^{2}=0.02\right]$, and integrity $\left[F(1,463)=14.85, p<0.001, \eta_{\mathrm{p}}{ }^{2}=0.02\right]$, but not ability $\left[F(1,463)=2.19, p=0.140, \eta_{\mathrm{p}}{ }^{2}=0.00\right.$; see Table 1]. In support of $\mathrm{H1a}$, pairwise comparisons revealed that high power-low status partners were rated as less trustworthy $(M=2.62, \mathrm{~S} E=0.10)$ than low power-low status partners $(M=3.08, S E=0.10, t(463)=-3.44, p<0.001,95 \%$ CI $[-0.73,-0.20])$, less benevolent $(M=2.77, S E=0.10)$ than low power-low status partners $(M=3.44, S E=0.10$, $t(463)=-4.77, p<0.001,95 \%$ CI $[-0.95,-0.40])$, and as having less integrity $(M=3.24, S E=0.08)$ than low powerlow status partners $(M=3.79, S E=0.08, t(463)=-4.60$, $p<0.001,95 \%$ CI $[-0.79,-0.32])$, but not for having less ability $(M=3.46, S E=0.10)$ than low power-low status partners $(M=3.50, S E=0.10, t(463)=-0.31, p=0.754,95 \%$ CI $[-0.31,0.22])$.

Moreover, both $\mathrm{H} 1 \mathrm{~b}$ and $\mathrm{H} 1 \mathrm{c}$ were supported for all four trust measures: pairwise comparison revealed that high power-low status partners were rated as less trustworthy than high power-high status partners $(M=4.33, S E=0.09$, $t(463)=-12.70, p<0.001,95 \%$ CI $[-1.97,-1.45])$ and low power-high status partners $(M=4.23, S E=0.10$, $t(463)=-11.79, p<0.001,95 \%$ CI $[-1.88,-1.35])$, less benevolent than high power-high status partners $(M=4.55$,
Table 1 Results of MANOVA of trustworthiness judgments in Studies 1 and 4

\begin{tabular}{|c|c|c|c|}
\hline Dependent variable & Independent variable & $F$ & $\eta_{\mathrm{p}}^{2}$ \\
\hline \multicolumn{4}{|l|}{ Study $1(n=467)$} \\
\hline \multirow[t]{3}{*}{ Trust } & Power & $3.80^{\dagger}$ & 0.00 \\
\hline & Status & $223.49 * * *$ & 0.32 \\
\hline & Power $\times$ Status & $8.53 * *$ & 0.01 \\
\hline \multirow[t]{3}{*}{ Benevolence } & Power & $7.50 * *$ & 0.01 \\
\hline & Status & $191.64 * * *$ & 0.28 \\
\hline & Power $\times$ Status & $16.07 * * *$ & 0.02 \\
\hline \multirow[t]{3}{*}{ Integrity } & Power & $7.03 * *$ & 0.01 \\
\hline & Status & $303.22 * * *$ & 0.39 \\
\hline & Power $\times$ Status & $14.85^{* * *}$ & 0.02 \\
\hline \multirow[t]{3}{*}{ Ability } & Power & 1.05 & 0.00 \\
\hline & Status & $237.92 * * *$ & 0.34 \\
\hline & Power $\times$ Status & 2.19 & 0.00 \\
\hline \multicolumn{4}{|l|}{ Study $4(n=253)$} \\
\hline \multirow[t]{3}{*}{ Trust } & Power & $6.93 * *$ & 0.03 \\
\hline & Status & $163.45^{* * *}$ & 0.40 \\
\hline & Power $\times$ Status & $5.91 *$ & 0.02 \\
\hline \multirow[t]{3}{*}{ Benevolence } & Power & $14.47 * *$ & 0.05 \\
\hline & Status & $133.47 * * *$ & 0.35 \\
\hline & Power $\times$ Status & $3.47^{\dagger}$ & 0.01 \\
\hline \multirow[t]{3}{*}{ Integrity } & Power & $15.30 * * *$ & 0.06 \\
\hline & Status & $170.56^{* * *}$ & 0.41 \\
\hline & Power $\times$ Status & $6.59 *$ & 0.03 \\
\hline \multirow[t]{3}{*}{ Ability } & Power & 1.29 & 0.01 \\
\hline & Status & $249.54 * * *$ & 0.50 \\
\hline & Power $\times$ Status & 0.04 & 0.00 \\
\hline
\end{tabular}

$* p<.05, * * p<.01, * * * p<.001$

$\dagger<0.10$;

$S E=0.10, t(463)=-12.68, p<0.001,95 \%$ CI $[-2.06$, - 1.51]) and low power-high status partners $(M=4.42$, $S E=0.10, t(463)=-11.55, p<0.001,95 \%$ CI $[-1.93$, - 1.37]), and as having less integrity than high powerhigh status partners $(M=5.04, S E=0.08, t(463)=-15.11$, $p<0.001,95 \%$ CI $[-2.03,-1.57])$ and low power-high status partners $(M=4.93, S E=0.09, t(463)=-13.99$, $p<0.001,95 \%$ CI $[-1.93,-1.46])$. Unlike H1a, H1b and H1c were supported for ability-based trust: high powerlow status partners were rated as having less ability than high power-high status partners $(M=5.08, S E=0.09$, $t(463)=-12.03, p<0.001,95 \%$ CI $[-1.89,-1.36])$ and low power-high status partners $(M=4.84, S E=0.10$, $t(463)=-10.06, p<0.001,95 \%$ CI $[-1.65,-1.11])$.

As our hypotheses involved multiple significance tests, it is possible that the family-wise error rate exceeded the 0.05 level. To address this possibility, we used the Tukey HSD test. The hypothesized effects of the structural paradox on distrust as compared to all conditions of power and status 
remained significant. All means (with standard errors) and condition contrasts are depicted in Fig. 1 (see Table 2).

These findings provide initial evidence for our first hypothesis that observers' perceptions of high power-low status actors predict lower levels of trust judgments. Indeed, we found that participants judged high power-low status actors as the least trustworthy compared to all combinations of status and power.

\section{Study 2: The Trust Game}

Study 2 was designed to replicate the results of Study 1 using a behavioral measure of (dis)trust. To do this, we used the trust game, an economic decision-making task that requires trusting others to reciprocate resources (Berg et al., 1995; Lount \& Pettit, 2012).

In the trust game, participants decide whether to send money to an anonymous partner to earn more money. The amount of money sent is tripled on its way to the partner, who can subsequently decide to send any amount back to the first player, including none. The more money participants initially send to their partner, the greater the amount they could potentially receive back from their partner. Consistent with the results of Study 1, we anticipated that high powerlow status partners will be sent less money than partners with any other power and status combination.

\section{Method}

\section{Participants}

We recruited 162 participants from MTurk (38\% females; $M_{\text {age }}=32.67, S D_{\text {age }}=9.92$ ) with the goal of averaging 40 per group (i.e., four groups) for economic reasons. Based on a sensitivity power analysis using the $\mathrm{G}^{*}$ power program (Faul et al., 2007) with this sample, a statistical power of $80 \%$ and an alpha level of 0.05 , the minimum effect that can be found is $f=0.221\left(\approx \eta_{\mathrm{p}}{ }^{2}=0.049\right)$. We conclude that the study was powered enough to detect a small to medium effect. Sample size was determined before any data analysis was conducted.
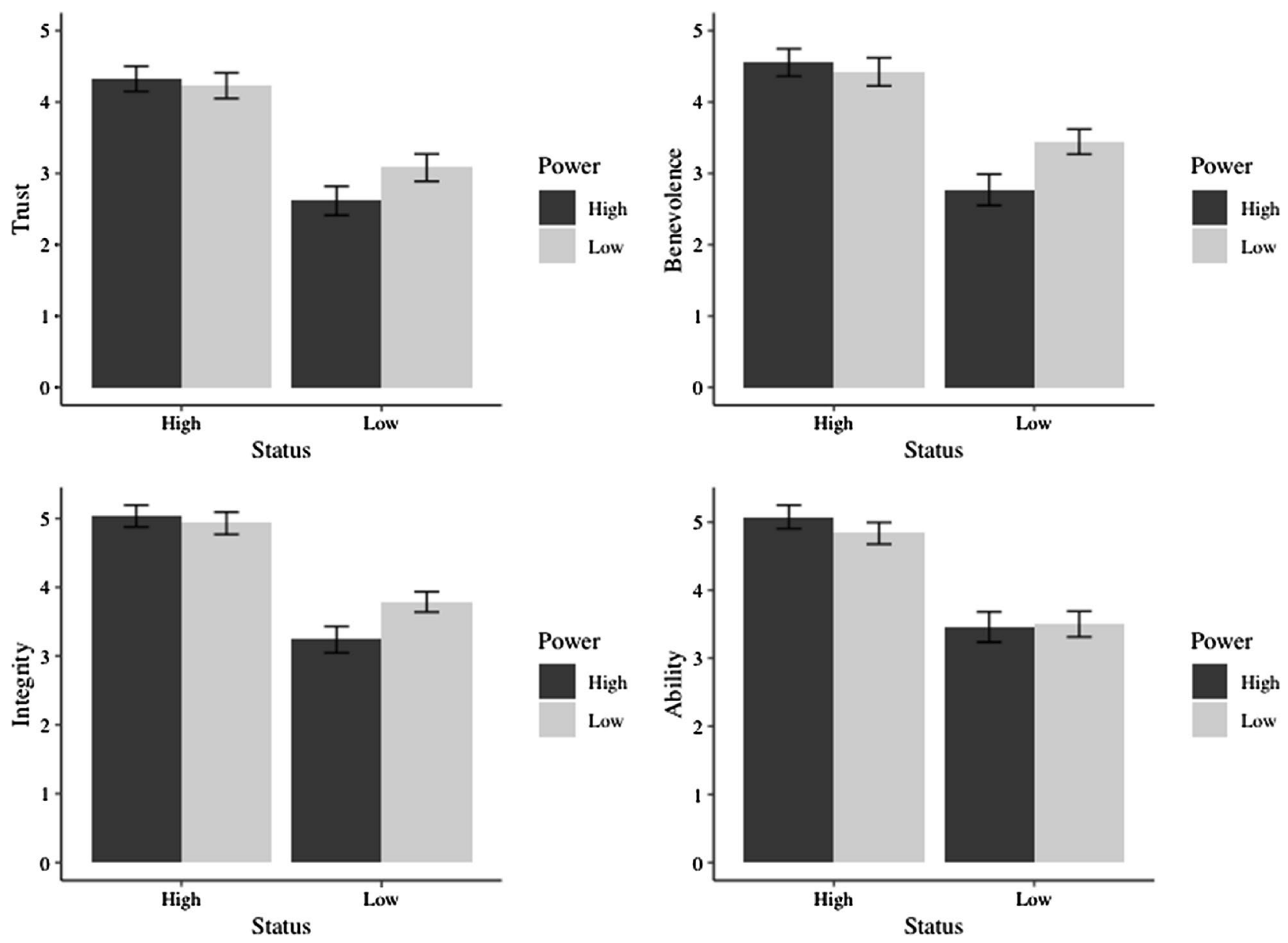

Fig. 1 Mean scores of trust judgments as a function of target actor's power and status (Study 1) 
Table 2 Means (Studies 1-3), logs odds (Study 4), and standard errors (in parentheses)

\begin{tabular}{|c|c|c|c|c|}
\hline & Dependent variable & Status & Power (High) & Power (Low) \\
\hline \multirow[t]{8}{*}{ Study $1(n=467)$} & \multirow[t]{2}{*}{ Trust } & High & $-4.33^{\mathrm{a}}(0.10)$ & $4.23^{\mathrm{a}}(0.10)$ \\
\hline & & Low & $2.62^{\mathrm{c}}(0.10)$ & $3.08^{\mathrm{b}}(0.10)$ \\
\hline & \multirow[t]{2}{*}{ Benevolence } & High & $4.55^{\mathrm{a}}(0.10)$ & $4.42^{\mathrm{a}}(0.10)$ \\
\hline & & Low & $2.77^{\mathrm{c}}(0.10)$ & $3.44^{\mathrm{b}}(0.10)$ \\
\hline & \multirow[t]{2}{*}{ Integrity } & High & $5.04^{\mathrm{a}}(0.08)$ & $4.93^{\mathrm{a}}(0.09)$ \\
\hline & & Low & $3.24^{\mathrm{c}}(0.09)$ & $3.79^{\mathrm{a}}(0.08)$ \\
\hline & \multirow[t]{2}{*}{ Ability } & High & $5.08^{\mathrm{a}}(0.10)$ & $4.84^{\mathrm{a}}(0.10)$ \\
\hline & & Low & $3.46^{\mathrm{b}}(0.10)$ & $3.50^{\mathrm{b}}(0.10)$ \\
\hline \multirow[t]{2}{*}{ Study $2(n=162)$} & \multirow[t]{2}{*}{ Behavioral trust } & High & $26.30^{\mathrm{a}}(3.07)$ & $18.80^{\mathrm{b}}(3.11)$ \\
\hline & & Low & $14.10^{\mathrm{b}}(3.15)$ & $26.80^{\mathrm{a}}(3.04)$ \\
\hline \multirow[t]{6}{*}{ Study $3(n=278)$} & \multirow[t]{2}{*}{ Trust Intent } & High & $46.10^{\mathrm{a}}(40.42)$ & $43.12^{\mathrm{a}}(34.11)$ \\
\hline & & Low & $39.70^{\mathrm{a}} *(36.35)$ & $54.38^{\mathrm{a} *}(34.64)$ \\
\hline & \multirow[t]{2}{*}{ Likeability } & High & $5.28^{\mathrm{a} *}(0.19)$ & $5.21^{\mathrm{ab}}(0.19)$ \\
\hline & & Low & $4.61^{\mathrm{b} *}(0.19)$ & $5.46^{\mathrm{a}}(0.18)$ \\
\hline & \multirow[t]{2}{*}{ Legitimacy } & High & $5.96^{\mathrm{a}}(0.18)$ & $5.28^{\mathrm{b}}(0.18)$ \\
\hline & & Low & $4.78^{\mathrm{b}}(0.18)$ & $5.10^{\mathrm{b}}(0.17)$ \\
\hline \multirow[t]{10}{*}{ Study $4(n=253)$} & \multirow[t]{2}{*}{ Trust } & High & $4.44^{\mathrm{a}}(0.13)$ & $4.47^{\mathrm{a}}(0.13)$ \\
\hline & & Low & $2.47^{\mathrm{c}}(0.13)$ & $3.14^{\mathrm{b}}(0.14)$ \\
\hline & \multirow[t]{2}{*}{ Benevolence } & High & $4.51^{\mathrm{a}}(0.15)$ & $4.81^{\mathrm{a}}(0.15)$ \\
\hline & & Low & $2.52^{\mathrm{c}}(0.15)$ & $3.37^{\mathrm{b}}(0.16)$ \\
\hline & \multirow[t]{2}{*}{ Integrity } & High & $4.94^{\mathrm{a}}(0.13)$ & $5.13^{\mathrm{a}}(0.13)$ \\
\hline & & Low & $2.86^{\mathrm{c}}(0.13)$ & $3.74^{\mathrm{b}}(0.14)$ \\
\hline & \multirow[t]{2}{*}{ Ability } & High & $5.34^{\mathrm{a}}(0.14)$ & $5.47^{\mathrm{a}}(0.14)$ \\
\hline & & Low & $3.01^{\mathrm{b}}(0.15)$ & $3.21^{\mathrm{b}}(0.15)$ \\
\hline & \multirow[t]{2}{*}{ Monitoring for cheating } & High & $-0.69^{\mathrm{a}}(0.26)$ & $-0.67^{\mathrm{a}}(0.26)$ \\
\hline & & Low & $1.37^{\mathrm{b}}(0.31)$ & $0.00^{\mathrm{a}}(0.26)$ \\
\hline
\end{tabular}

The letters a-c represent Tukey HSD-corrected differences between groups. Values with different letters significantly differ from each other at $p<0.05$ or lower

*Values are marginally different
All participants were screened with the same attention check procedure as Study 1.

\section{Procedure}

Similar to Study 1, participants were informed that they would be participating in a test of a new collaboration platform. Participants were paired with a fictitious partner in a 2 (status: high vs. low) $\times 2$ (power: high vs. low) betweensubject design and given the same status and power feedback as Study 1. Participants then completed the same two manipulation check questions used in Study 1.

Next, participants were awarded a $\$ 0.50$ bonus and were informed that they could assign some fraction (i.e., none, some or all) of their $\$ 0.50$ bonus to their fictitious partner. Participants learned that the amount sent would be tripled on its way to the partner, and the partner would then decide how much of the bonus to keep for themselves and how much to send back to the participant. The game created an opportunity for the participant to accrue more money depending on the amount they chose to send to the partner. For example, if participants sent the entire $\$ 0.50$, the amount would be tripled to $\$ 1.50$. Should the partner send back half, the participant would be better off with $\$ 0.75$ as opposed to the initial amount of $\$ 0.50$. Thus, the amount participants' sent to the partner served as our measure of behavioral trust in line with existing research (ex. Lount \& Pettit, 2012; Pillutla et al., 2003).

Once the amount was chosen, participants were informed of technical difficulties with the online platform and that their partner was no longer online. Participants were awarded a $\$ 1.00$ bonus as compensation for the difficulties encountered. Finally, participants completed demographic items and were debriefed.

\section{Results and Discussion}

\section{Manipulation Check}

A manipulation check was performed confirming that the status manipulation worked as expected $(F(1,160)=113.37$, 
$\left.p<0.001, \eta_{\mathrm{p}}{ }^{2}=0.41\right)$. Participants perceived that high status partners had more status $(M=4.96, S E=0.13)$, than low status partners $(M=3.09, S E=0.13), t(160)=10.65$, $p<0.001,95 \%$ CI $[1.53,2.22])$. Similarly, the power manipulation worked as expected $(F(1,160)=44.03, p<0.001$, $\left.\eta_{\mathrm{p}}{ }^{2}=0.22\right)$; participants perceived high power partners to have more power $(M=4.72, S E=0.14)$ than low power partners $(M=3.43, S E=0.14, t(160)=6.64, p<0.001,95 \% \mathrm{CI}$ $[0.91,1.68])$.

\section{Behavioral Distrust}

To test our first hypothesis, we conducted a two-way ANOVA using the amount participants sent to their partner from the payment they were awarded $(\$ 0.50)$ as the dependent variable. The results of the ANOVA yielded a significant status $\times$ power interaction $(F(1,158)=10.79, p=0.001$, $\eta_{\mathrm{p}}{ }^{2}=0.06$; see Fig. 2). In support of H1a, pairwise comparisons indicated that high power-low status partners were sent less money $(M=14.10, S E=3.15)$ than low power-low status partners $(M=26.80, S E=3.04, t(158)=-2.91, p=0.004$, 95\% CI [-21.38, - 4.09]). Further, H1b was supported: We found significant differences in the amount of money sent to high power-low status partners and high power-high status partners $(M=26.30, S E=3.07, t(158)=-2.79, p=0.006$, 95\% CI [- 20.98, - 3.60]). However, H1c was not supported: We did not find significant differences in the amount of money sent to high power-low status and low powerhigh status partners $(M=18.80, S E=3.11, t(158)=-1.07$, $p=0.290,95 \%$ CI $[-13.45,4.05])$.

As in Study 1, we applied the Tukey HSD test to our multiple comparisons. The hypothesized effect of the structural paradox on distrust compared to the low power-low status (H1a) and the high power-high status conditions (H1b) remained significant (see Fig. 2; Table 2 for all comparisons).

These results provide additional support for $\mathrm{H} 1 \mathrm{a}$ and $\mathrm{H} 1 \mathrm{~b}$ by replicating the interaction results for trust judgments found in Study 1 such that the combination of high powerlow status is less beneficial for trusting behaviors than low power-low status and high power-high status. Although in Study 1 high power-low status partners were judged as less trustworthy than low power-high status partners, this effect did not replicate in Study 2. In Study 3 we offer an explanation for this result.

\section{Study 3: Trust Intent}

In study 3 we sought to alleviate concerns regarding two limitations of the previous studies. First, because Studies 1 and 2 provided explicit information about the target's power and status, there is a possibility that participants' distrust was an artifact of the design manipulation. To
Fig. 2 Mean number of bonus points sent to one's partner (representing up to \$.0.50) as a function of partner's power and status (Study 2)

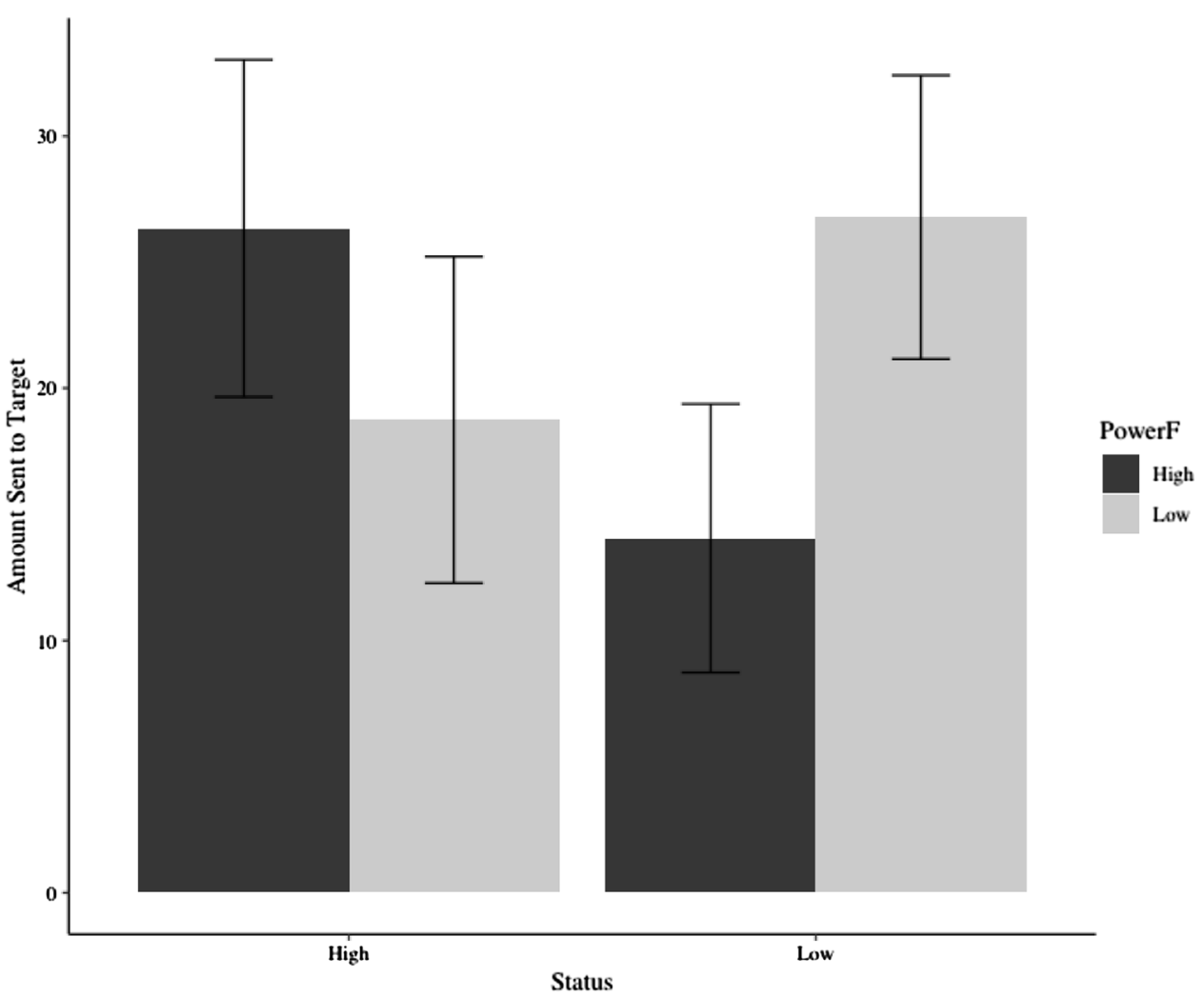


increase generalizability, we used a sample of working adults to assess how a colleague's level of power and status, derived from their organizational position, affects the amount of money sent them in a hypothetical trust game.

Second, it is possible that (il)legitimacy inherent to the structural paradox and/or a target's likeability played a role (or roles) in our findings. Legitimacy captures the appropriateness of hierarchical differentiation (Halevy et al., 2011; Tyler, 2006); the benefits of legitimacy on trust have been discussed in both organizational and law enforcement contexts (Colquitt et al., 2012; Tyler et al., 2015). Likeability refers to how well an actor is socially accepted and welcomed by the group (Huo et al., 2010). While likeability is conceptually and empirically distinct from status (Anderson et al., 2012; Huo et al., 2010), both constructs evoke positive evaluations and have been associated with similar outcomes (i.e., subjective well-being). However, dislike has been linked to violations in expected patterns, forms, and individuals (Gollwitzer et al., 2020; Proulx et al., 2012). For example, people experience aversive arousal toward others who deviate in their appearance (i.e., dwarfism, physical disability), their groups (i.e., racial minorities), and their socioeconomic status) from regular expectations (Gollwitzer et al., 2017). Because we argue that the structural paradox violates observers' expectations between low status and high power (rather than illegitimacy), a finding of dislike directed at high powerlow status actors would support our theoretical argument.

To address these concerns, we added measures of targets' role legitimacy and likeability and tested whether they mediate the relationship between (dis)trust and the structural paradox.

\section{Method}

\section{Participants}

We performed power calculations before data was collected using the $G^{*}$ power program (Faul et al., 2007) to determine sample size. For a moderate effect size $(f=0.25)$ with $\alpha=0.01$ in a $2 \times 2$ design ( 4 groups, numerator $\mathrm{df}=1$ ) and power of 0.95 , we would require a total sample size of 289 participants. The sample was collected from Prolific Academic. All participants were screened with an attention check leaving a final sample of 278 participants (72\% females; $\left.M_{\text {age }}=36.32, S D_{\text {age }}=12.24\right)$. A sensitivity power analysis revealed that the study was powered to detect a medium effect size $\left(f=0.267 ; \approx \eta_{\mathrm{p}}{ }^{2}=0.066\right)$ assuming an alpha level of 0.01 and $95 \%$ power. On average, participants had more than 15 years of work experience and a bachelor's degree or higher.

\section{Procedure}

As in the two previous studies, participants were randomly assigned to one of four conditions in a 2 (status: high vs. low) $\times 2$ (power: high vs. low) between-subjects design. First, participants read a prompt in which they recalled a person from their workplace who has power (high or low) and status (high or low). In the high power-low status prompt, they read the following: "Please think about an individual you have contact with in your workplace that has a high power, low status position. By 'high power position' we mean the person's role gives them control over resources that you need or desire in your job (e.g., compensation, personnel, budget, information, your tasks, your schedule, etc.). By 'low status position' we mean that the person's role is NOT held in high regard or esteem in the organization. You will be asked to answer some questions about your relationship with this person, so it should be someone that you come into contact with during the course of your job."

Participants were asked to write the initials of the individual they selected and briefly describe their role in the workplace in terms of their power and status. Participants were then told to imagine that they had been awarded a $\$ 100$ bonus and to imagine playing the trust game with the colleague they had recalled and identified. Participants were asked to assign some fraction (i.e., none, some, or all) of the $\$ 100$ bonus to their colleague; they were also asked to imagine that the money would be sent anonymously to their colleague so there would be no interpersonal consequences. The amount participants specified served as our measure of trust intent. Next, participants were asked to indicate the extent to which they felt that their colleague's role at work was assigned in a fair manner (i.e., legitimacy, adopted from Hays \& Blader, 2017) and the extent to which they liked their colleague on a Likert scale $(1=$ not at all to $7=$ very much so).

\section{Results}

To test our first hypothesis, we conducted a two-way ANOVA of trust intent-the amount participants sent to their colleague from their hypothetical award (\$100) —as the dependent variable. The results of the ANOVA yielded a significant status $\times$ power interaction $(F(1,265)=3.94$, $p=0.048, \eta_{\mathrm{p}}{ }^{2}=0.01$; see Fig. 3). In support of H1a, pairwise comparisons indicated that high power-low status partners were sent less money $(M=39.70, S E=4.48)$ than low powerlow status partners $(M=54.40, S E=4.32, t(265)=-2.36$, $p=0.019,95 \%$ CI $[-26.95,-2.42])$. However, H1b and H1c were not supported: We did not find significant differences between high power-low status and high powerhigh status partners $(M=46.10, S E=4.48, t(265)=-1.01$, $p=0.314,95 \% \mathrm{CI}[-18.88,6.09])$ or low power-high status 
Fig. 3 Mean number of hypothetical bonus dollars sent to one's work colleague (representing up to \$100) as a Function of Colleague's Power and Status (Study 3)

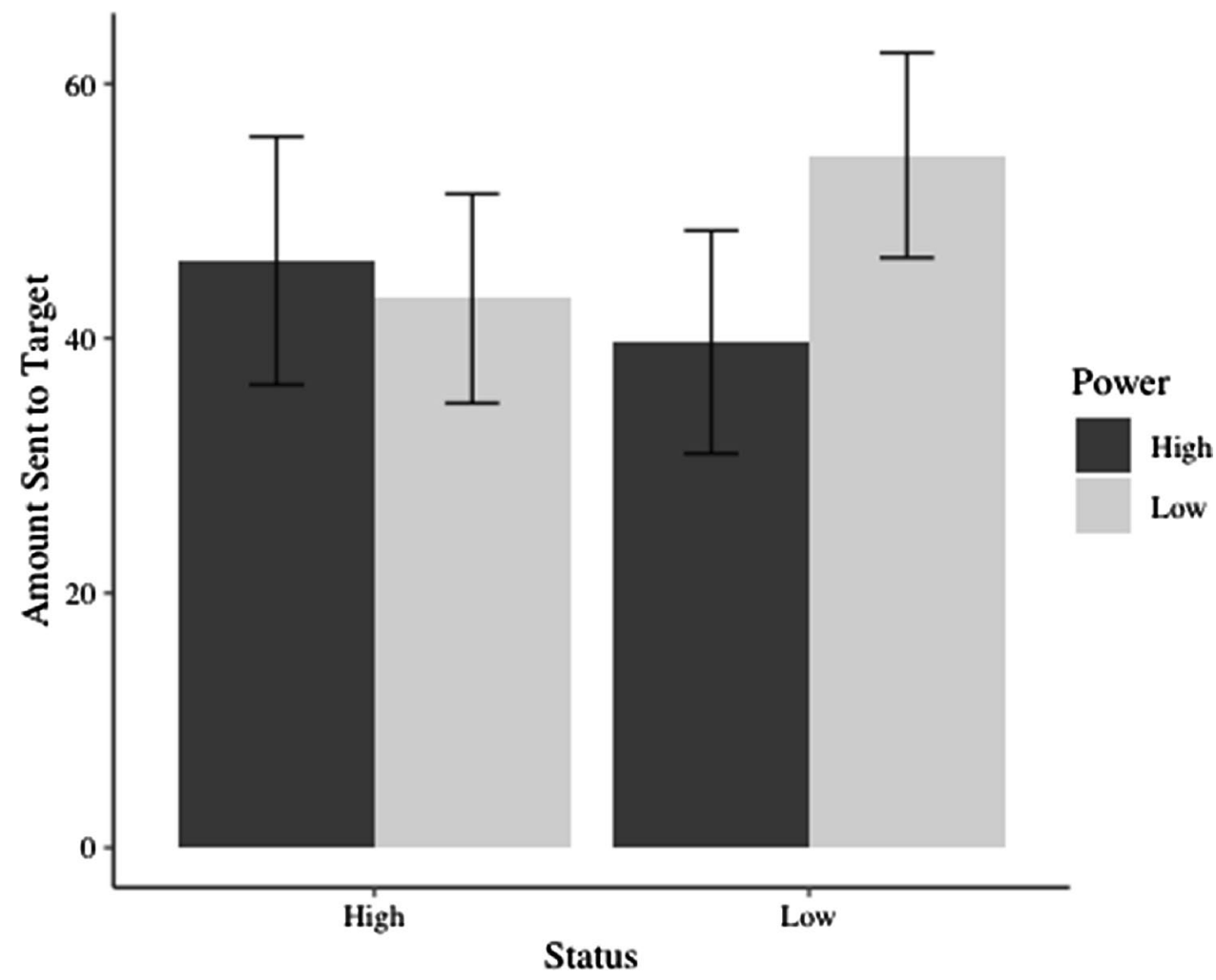

partners $(M=43.10, S E=4.48, t(265)=-0.54, p=0.590$, 95\% CI $[-15.91,9.06])$.

As in our previous studies, we applied the Tukey HSD test. The hypothesized effect of the structural paradox on distrust as compared to the low power-low status condition became marginally significant $(p=0.088)$. See Fig. 2 ; Table 2 for all comparisons.

\section{Likeability Ratings}

The results of a two-way ANOVA yielded a significant main effect for power $\left(F(1,274)=4.32, p=0.039, \eta_{\mathrm{p}}{ }^{2}=0.02\right)$ but not for status $\left(F(1,274)=1.22, p=0.271, \eta_{\mathrm{p}}{ }^{2}=0.00\right)$. These results were qualified by a significant status $\times$ power interaction $\left(F(1,274)=5.99, p=0.015, \eta_{\mathrm{p}}{ }^{2}=0.02\right)$. Pairwise comparisons showed that high power-low status partners were judged as less likable $(M=4.61, S E=0.19)$ compared to: low power-low status $(M=5.46, S E=0.18, t(274)=-3.22$, $p=0.001,95 \%$ CI $[-1.37,-0.33])$, high power-high status partners $(M=5.28, S E==0.19, t(274)=-2.50, p=0.013$, $95 \%$ [CI $-1.19,-0.14])$, and low power-high status partners $(M=5.21, S E=0.19,(t(265)=-2.23, p=0.026,95 \%$ CI $[-1.12,-0.07]$. After applying the Tukey HSD test, the effect of the structural paradox on likeability as compared to the low power-low status condition remained significant, while the comparison with the high power-high status condition became marginally significant $(p=0.062)$ and was not significant as compared to the low power-high status condition $(p=0.117)$ (see Table 2).

\section{Role Legitimacy Ratings}

The results of a two-way ANOVA yielded a significant main effect for status $\left[F(1,274)=15.12, p<0.001, \eta_{\mathrm{p}}{ }^{2}=0.05\right]$ but not for power $\left[F(1,274)=1.08, p=0.299, \eta_{\mathrm{p}}{ }^{2}=0.00\right]$. The results of a two-way ANOVA yielded a significant status $\times$ power interaction $[F(1,274)=8.09, p=0.005$, $\left.\eta_{\mathrm{p}}{ }^{2}=0.03\right]$. Pairwise comparisons showed that a high powerlow status role was judged as less legitimate $(M=4.78$, $S E=0.18)$ compared to the high power-high status role $(M=5.96, S E==0.18, t(274)=-4.75, p<0.001,95 \% \mathrm{CI}$ $[-1.81,-0.53])$. No such effect was found between the high power-low status and the low power-low status role $(M=5.10, S E=0.17, t(274)=-1.29, p=0.573,95 \% \mathrm{CI}$ $[-0.95,0.32])$ and the low power-high status role $(M=5.28$, $S E=0.18,(t(265)=-2.00, p=0.190,95 \%$ CI $[-0.15$, 1.14]) (see Table 2). After applying the Tukey HSD test, the effect of the structural paradox on legitimacy as compared to the high power-high status condition remained significant (see Table 2).

\section{Mediation Analysis}

To examine whether the interactive effect of status and power on trust intent was mediated by legitimacy and 
likeability, we conducted a moderated mediation analysis following a bootstrapping procedure using the R PROCESS macro with 5000 iterations (model 8; Hayes, 2017). In the analysis, legitimacy and likeability were included as simultaneous mediators ( $r=0.56, p<0.001$; Fig. 4). The analysis revealed that the effect of the status $\times$ power interaction on trust intention was significant via likeability $(B=-8.33$, $S E_{\text {boot }}=3.49,95 \%$ [CI $\left.\left.-15.70,-1.92\right]\right)$, but not via legitimacy $\left(B=-1.02, S E_{\text {boot }}=1.78,95 \%\right.$ [CI $\left.\left.-5.08,2.05\right]\right)$. Within the mediated moderation model, the direct effect of the status $\times$ power interaction on trust intent was not significant $(B=-8.31, S E=8.42, p=0.325,95 \%$ CI $[-24.89$, $8.28]$ ) indicating full mediation. The model further indicates that for low status targets, high power predicted significantly less money sent via lower likeability (stronger dislike) $\left(B=-5.91, S E_{\text {boot }}=2.57,95 \%\right.$ CI $\left.[-11.20,-1.25]\right)$. There was no evidence of such an effect among low powerlow status targets $\left(B=2.42, S E_{\text {boot }}=2.15,95 \%\right.$ CI $[-1.65$, 6.89]). Among high power targets, the indirect effect via lower likeability was significant for those with low status (high power-low status) $\left(B=-7.10, S E_{\text {boot }}=2.62,95 \% \mathrm{CI}\right.$ $[-12.59,-2.34])$ but was not significant for those with high status (high power-high status) $\left(B=1.23, S E_{\text {boot }}=2.19\right.$, $95 \%$ CI $[-2.86,5.79])$.

\section{Discussion}

These results expand upon Studies 1 and 2 by shedding light on why the structural paradox leads to greater distrust. We find that dislike of high power-low status targets, rather than perceived (il)legitimacy of their role, predicted lower trust intentions as compared to other low status targets (low power-low status) and other high status targets (high power-high status). This finding suggests that the structural paradox evokes an adverse reaction; the results of the moderated mediation analysis further provide support for the idea that this reaction drives observers' distrust.

When examining the simple effects in the ANOVA model, high power-low status was significantly different from low power-low status in support of H1a. However, both $\mathrm{H} 1 \mathrm{~b}$ and $\mathrm{H} 1 \mathrm{c}$ were not supported; we did not find significant effects between high power-low status and the two remaining conditions (i.e., low power-high status and high power-high status). In hindsight, it is possible that targets' power confounded trusting behaviors affecting participants' willingness to send money. That is, within the trust game, participants must decide to give away control over a monetary resource (i.e., their power) with the expectation that the other party will give back control at the end of the game (Mooijman et al., 2019); thus, targets also had power over the participants. This may explain why we did not replicate Study 1's results in both Studies 2 and 3. Removing the target's power, in other words, could have led to significant differences between high power-low status and all power and status conditions (as in Study 1).

In the next study, we use a manipulation of trust-related behavior in which targets do not have power over the participants.

\section{Study 4: Monitoring for Cheating}

The goal of Study 4 was twofold. First, we tested H2a, H2b and H2c: whether the structural paradox predicts greater monitoring for cheating of high power-low status actors than actors with all other combinations of power and status. Second, we tested $\mathrm{H} 3$ for the proposed mechanism: whether trust judgments will mediate a tendency for greater monitoring of high power-low status actors.
Fig. 4 Mediation analysis (Study 3). Observers' likeability judgments fully mediate the interactive effect of the target actor's status and power on trust intentions (Study 3). Unstandardized coefficients $(b)$ are presented; $c$ ' is the direct effect with mediators in the model. Only the indirect effect via likeability was significant with 5000 bootstrapped resamples $=-8.33, S E_{\text {boot }}=3.51,95 \%$ CI $[-15.74,-2.05] . * p<.05$, $* * p<.01, * * * p<.001$

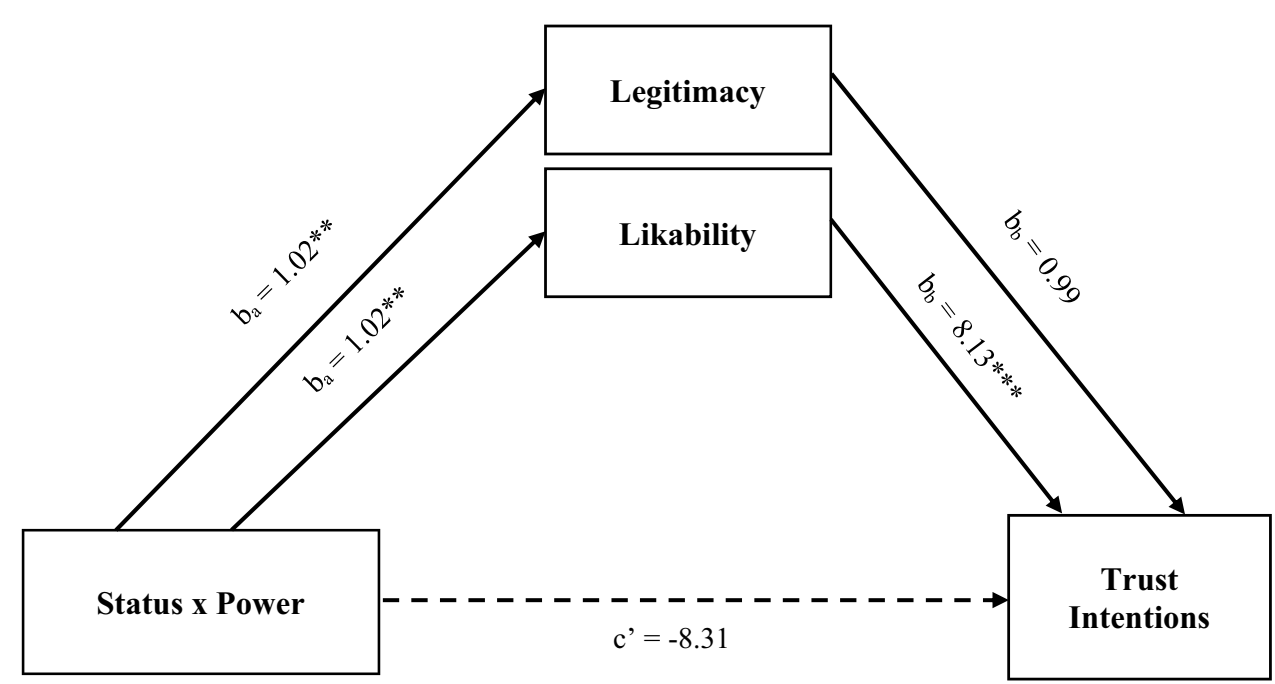




\section{Method}

\section{Participants}

We performed power calculations before data was collected using the $\mathrm{G}^{*}$ power program (Faul et al., 2007) to determine sample size. For a moderate effect size $(f=0.25)$ with $\alpha=0.01$ in a $2 \times 2$ design ( 4 groups, numerator $\mathrm{df}=1$ ) and power of 0.95 , we would require a total sample size of 289 participants. All participants were screened with the same attention check procedure as in Studies 1 and 2 leaving a final sample of 253 participants from MTurk (60\% females; $M_{\text {age }}=35.17, S D_{\text {age }}=11.59$ ). A sensitivity power analysis revealed that the study was powered to detect a medium effect size $\left(f=0.267 ; \approx \eta_{\mathrm{p}}{ }^{2}=0.066\right)$ assuming an alpha level of 0.01 and $95 \%$ power.

\section{Procedure}

As in Studies 1 and 2, participants were randomly assigned to one of four manipulated conditions in a 2 (status: high vs. low) $\times 2$ (power: high vs. low) between-subjects design. Participants were informed that they would be participating in a study investigating whether people could detect cheating behavior in others using a paradigm developed by Fast et al. (2012). Participants read a short description of a research study that had been conducted in our lab. The study described a group of four participants working on a team to improve the profitability of a troubled manufacturing plant. Participants read feedback about one of the team members, with initials "B.R.". The content of the feedback served to manipulate high and low levels of B.R.'s status and power. In the high (low) power condition, B.R. was described as having the manager (assistant) role on the team, which was described as having total (no) control over how the work of the team was completed and how each member was evaluated. In the high status (low) status condition, B.R. was described as the most (least) respected and valued person on the team by his teammates.

As a manipulation check, participants rated how much status and power they thought B.R. had, using the same measures as Study 1. In addition, participants rated their impression of B.R.'s trustworthiness judgments using the same measures as Study 1.

Next, we described a situation where B.R. could act dishonestly (based on a cheating paradigm used in ethics research; see Vohs \& Schooler, 2008). Participants learned that B.R. worked on a task that required solving twenty math problems each within ten seconds (or less) in the experimenters' computer lab. Each math problem was worth a $\$ 0.25$ bonus for a possible total bonus of \$5.00. Participants were informed of a computer glitch that allowed B.R. to see the correct answer. They were also informed that this could be prevented by pressing the space bar after each problem appeared so that the answer would not be revealed. B.R. was informed of the glitch and was asked to solve the problems honestly by pressing the space bar each time a math problem appeared on the screen. Participants learned that B.R. selfreported that none of the answers were revealed because he/ she pressed the space bar all 20 times to block the answer from appearing. In addition, B.R. self-reported a score of 16 out of the 20 problems earning him/her a $\$ 4.00$ bonus (out of a possible \$5.00).

Participants were then informed that, unbeknownst to B.R., the computer program had kept track of the number of times B.R. had pressed the space bar. Participants were then given a choice whether to check B.R.'s self-report against the results of the computer program or to believe B.R.'s self-reported answer. In order to make this choice consequential, participants learned that they would be awarded a $\$ 1.00$ bonus if they correctly detected cheating but would not get the bonus if they monitored B.R. for cheating but no cheating occurred. The dependent variable was whether participants chose to check B.R.'s self-reported answer. Once they made their choice, all participants were awarded the bonus. Lastly, participants completed demographic items and were debriefed.

\section{Results and Discussion}

\section{Status and Power Manipulation Check}

Confirming that the status manipulation worked as expected $\left(F(1,251)=651.19, p<0.001, \eta_{\mathrm{p}}{ }^{2}=0.72\right)$, participants perceived that high status partners had more status $(M=6.01$, $S E=0.11)$ than low status partners $(M=1.84, S E=0.12$, $t(251)=25.52, p<0.001,95 \%$ CI [3.85, 4.49]). Similarly, the power manipulation worked as expected $(F(1,251)=369.95$, $\left.p<0.001, \eta_{\mathrm{p}}{ }^{2}=0.60\right)$, participants perceived high power partners to have more power $(M=5.92, S E=0.13)$, than low power partners $(M=2.33, S E=0.13, t(251)=19.23$, $p<0.001,95 \%$ CI $[3.22,3.96])$.

\section{Trust Judgments}

We conducted a two-way MANOVA on the four trust scales (i.e., benevolence, integrity, ability, and general trust). We found significant main effects for both status (Wilk's $\left.\lambda=0.49, F(4,246)=65.06, p<0.001, \eta_{\mathrm{p}}{ }^{2}=0.52\right)$ and power (Wilk's $\lambda=0.89, F(4,246)=7.38, p<0.001, \eta_{\mathrm{p}}{ }^{2}=0.06$ ). These results were qualified by a significant power $\times$ status interaction (Wilk's $\lambda=0.93, F(4,246)=4.44, p=0.002$, $\left.\eta_{\mathrm{p}}{ }^{2}=0.07\right)$.

Univariate analysis showed that the hypothesized interaction of status and power was significant for general trust $\left(F(1,249)=5.91, p=0.016, \eta_{\mathrm{p}}{ }^{2}=0.02\right)$ and integrity $(F(1$, 
249) $\left.=6.59, p=0.011, \eta_{\mathrm{p}}{ }^{2}=0.03\right)$, marginally significant for benevolence $\left(F(1,249)=3.47, p=0.064, \eta_{\mathrm{p}}{ }^{2}=0.01\right)$, but not significant for ability $\left(F(1,249)=0.04, p=0.836, \eta_{\mathrm{p}}{ }^{2}=0.00\right)$ (see Table 1). In support of H1a, pairwise comparisons revealed that high power-low status partners were rated as less trustworthy $(M=2.47, \mathrm{~S} E=0.13)$ than low powerlow status partners $(M=3.14, S E=0.14, t(249)=-3.58$, $p<0.001,95 \%$ CI $[-1.04,-0.30])$, less benevolent $(M=2.52, S E=0.15)$ than low power-low status partners $(M=3.37, S E=0.16, t(249)=-3.98, p<0.001,95 \% \mathrm{CI}$ $[-1.28,-0.43])$, and as having less integrity $(M=2.86$, $S E=0.13)$ than low power-low status partners $(M=3.74$, $S E=0.14, t(249)=-4.56, p<0.001,95 \%$ CI $[-1.26$, $-0.50])$, but not for having less ability $(M=3.01, S E=0.15)$ than low power-low status partners $(M=3.21, S E=0.15$, $t(249)=-0.94, p=0.349,95 \%$ CI $[-0.61,0.22])$.

Moreover, H1a and $\mathrm{H} 1 \mathrm{~b}$ were supported for all four trust measures: high power-low status partners were rated as less trustworthy than high power-high status $(M=4.44$, $S E=0.13, t(249)=-10.87, p<0.001,95 \%$ CI $[-2.32$, - 1.61]) and low power-high status partners $(M=4.47$, $S E=0.13, t(249)=-11.30, p<0.001,95 \%$ CI $[-2.36$, - 1.65]), less benevolent than high power-high status $(M=4.51, S E=0.15, t(249)=-9.58, p<0.001,95 \%$ CI $[-2.41,-1.59])$ and low power-high status partners $(M=4.81, S E=0.15, t(249)=-10.98, p<0.001,95 \% \mathrm{CI}$ $[-2.71,-1.89])$, and as having less integrity than high power-high status $(M=4.94, S E=0.13, t(249)=-11.16$, $p<0.001,95 \%$ CI $[-2.44,-1.71])$ and low power-high status partners $(M=5.13, S E=0.13, t(249)=-12.14$, $p<0.001,95 \%$ CI $[-2.64,-1.90])$, and for having less ability than high power-high status $(M=5.34, S E=0.14$, $t(249)=-11.47, p<0.001,95 \%$ CI $[-2.73,-1.93])$ and low power-high status partners $(M=5.47, S E=0.14$, $t(249)=-12.10, p<0.001,95 \%$ CI $[-2.87,-2.06])$.

As in the previous studies, we applied the Tukey HSD test. The hypothesized effects of the structural paradox on distrust as compared across all conditions of power and status remained significant. All means (with standard errors) are depicted in Fig. 5 (see also Table 2).

\section{Monitoring for Cheating}

To test our second hypothesis, we used a binary logistic regression predicting the likelihood of choosing to monitor B.R. $(0=$ not monitored, $1=$ monitored $)$. Results revealed a significant main effect of status $(B=-0.68, S E=0.14$, $Z=-4.97, \mathrm{OR}=0.51, p<0.001,95 \%$ CI $[-0.96,-0.42])$ indicating that the odds of monitoring for cheating in the high status condition significantly decreases by a factor of 0.51 (exp -0.68$)$ than in the low status condition. We also found a significant main effect of power $(B=0.34$, $S E=0.14, Z=2.44, \mathrm{OR}=1.40, p=0.015,95 \%$ CI $[0.07$,
0.61]) indicating that the odds of monitoring in the high power condition significantly increases by a factor of 1.40 (exp 0.34) than in the low power condition.

As hypothesized, the status by power interaction was significant $(B=-0.35, S E=0.14, Z=-2.53, \mathrm{OR}=0.71$, $p=0.012,95 \%$ CI $[-0.62,-0.08])$ and replicated the results of the previous studies. Pairwise comparisons showed that the probability of monitoring for cheating in the high power-low status condition was higher $(P=80 \%)$ than in the low power-low status condition (H2a; $P=50 \%, Z=3.36$, $\left.p<0.001, \mathrm{OR}=0.26,95 \% \mathrm{CI}_{\mathrm{OR}}[0.12,0.57]\right)$, the high power-high status condition (H2b; $P=33 \%, Z=-5.08$, $\left.p<0.001, \mathrm{OR}=7.85,95 \% \mathrm{CI}_{\mathrm{OR}}[3.54,17.38]\right)$, and the low power-high status condition (H2c; $P=34 \%, Z=5.01$, $\left.p<0.001, \mathrm{OR}=0.13,95 \% \mathrm{CI}_{\mathrm{OR}}[0.06,0.29]\right)$.

As in the previous studies, we applied the Tukey HSD test. The hypothesized effect of the structural paradox on monitoring for cheating as compared across all conditions of power and status remained significant. All probabilities are depicted in Fig. 6 (see also Table 2).

\section{Mediation Analysis}

To test whether the interactive effect of status and power on monitoring for cheating is mediated by trust judgments (H3), we first averaged the three trust measures which were significant with respect to the structural paradox and all conditions of power and status - general trust, benevolence, and integrity-into a global measure of (dis)trust ( 15 items; $\alpha=0.96$ ). We then tested a mediated moderation model following a bootstrapping procedure using the R PROCESS macro with 5000 iterations (model 8; Hayes, 2017).

The indirect effect of the status $\times$ power interaction on the likelihood of being monitored for cheating through the trust measure was significant $\left(B=0.35, S E_{\mathrm{bot}}=0.18,95 \%\right.$ CI $[0.06,0.73])$. Within the mediated moderation model (Fig. 7), the direct effect of the status $\times$ power interaction was significant $\left(B=1.12, S E_{\text {boot }}=0.57, p=0.050,95 \%\right.$ CI $[0.01,2.24])$ indicating partial mediation. Among low status partners, the indirect effect of being monitored for cheating via trust judgments (higher distrust judgments) was stronger for partners with high power (high power-low status; $B=1.10, S E_{\mathrm{boot}}=0.35,95 \%$ CI $\left.[0.53,1.91]\right)$ than for those with low power (low power-low status; $B=0.76$ $S E_{\text {boot }}=0.26,95 \%$ CI $\left.[0.34,1.38]\right)$. Among high power partners, the indirect effect via trust judgements was significant for those with low status (high power-low status; $B=0.45$, $S E_{\text {boot }}=0.17,95 \%$ CI $\left.[0.18,0.84]\right)$ but was not significant for those with high status (high power-high status; $B=0.10$, $S E_{\text {boot }}=0.11,95 \%$ CI [ - 0.08, 0.34]).

These findings replicate and extend the results of Studies 1through 3 by further demonstrating that high power-low status targets are significantly more likely to be monitored 

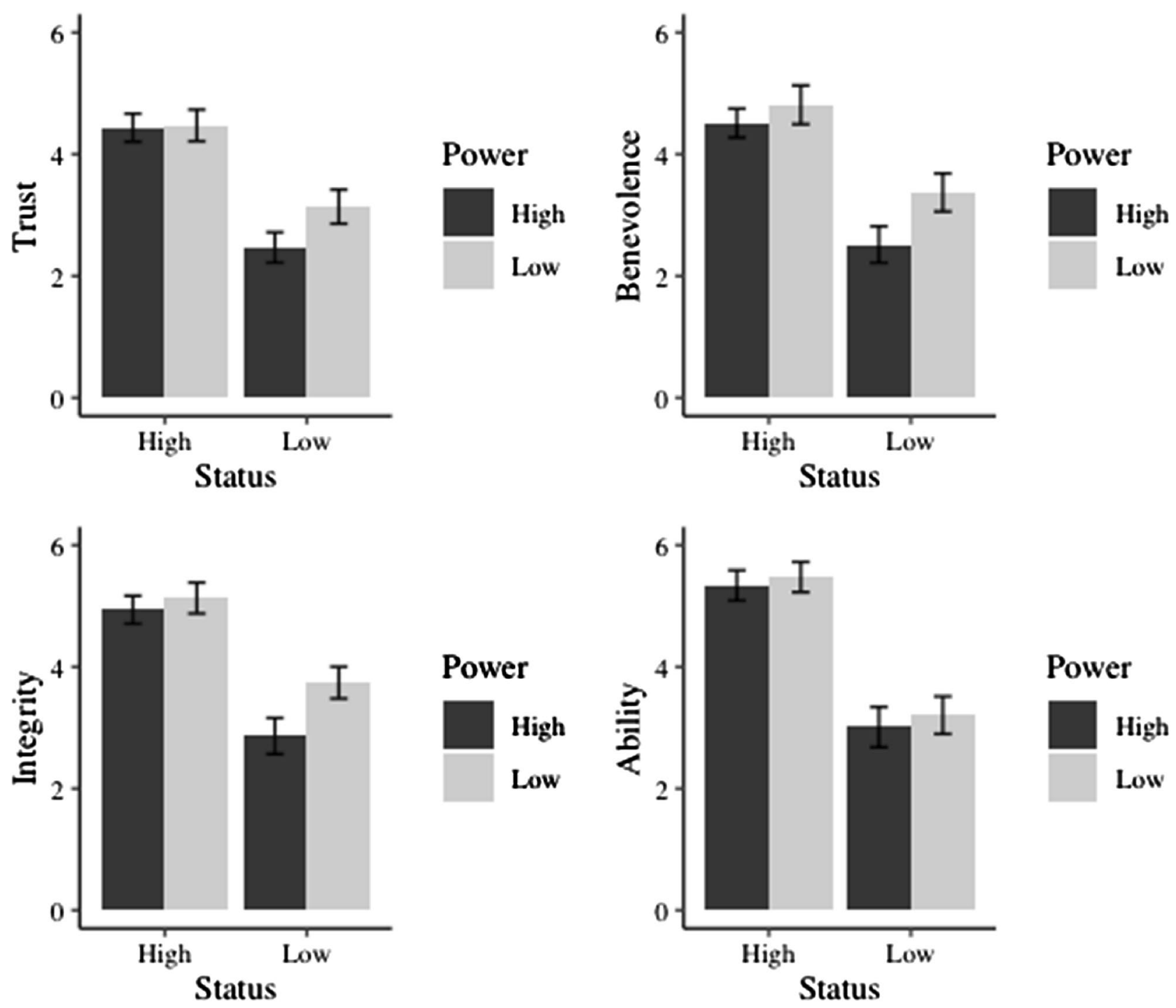

Fig. 5 Mean scores of trust judgments as a function of target actor's power and status (Study 4)

for cheating than targets with all other combinations of status and power. Further, this result is partially dependent on trust judgments. In other words, we found evidence that high power-low status actors are more likely, on average, to experience distrust and monitoring.

\section{Internal Meta-analysis}

We have reported results from four experimental studies testing the effect of the structural paradox on distrust as compared to all other combinations of power and status. Results showed that in two of the studies, the hypothesized effect of the structural paradox on distrust as compared to high power-high status (Study 2; H1b) and low power-low status (Study 3; H1a) became marginally significant with a Tukey
HSD correction. Additionally, in both Studies 2 and 3, the hypothesized effect of the structural paradox on distrust as compared to low power-high status (H1c) was not supported.

In order to evaluate the strength of these effects, we conducted an internal meta-analysis which included trust measures from Studies 1 to $4(N=1160$; Studies 1 and 4's three measures of trust-benevolence, integrity and general trust). An internal meta-analysis allowed us to examine the reliability of the findings in the direction of the hypothesized effect for our first hypothesis (H1a, H1b, and H1c) and to rule out alternative explanations such as a general incongruency effect between status and power in both directions (i.e., high power-low status and low power-high status). That is, we sought to examine whether the distrust leveled at high power-low status actors is significantly different from all 
Fig. 6 Probability of monitoring the target actor for cheating as a function of actor's power and status (Study 4)

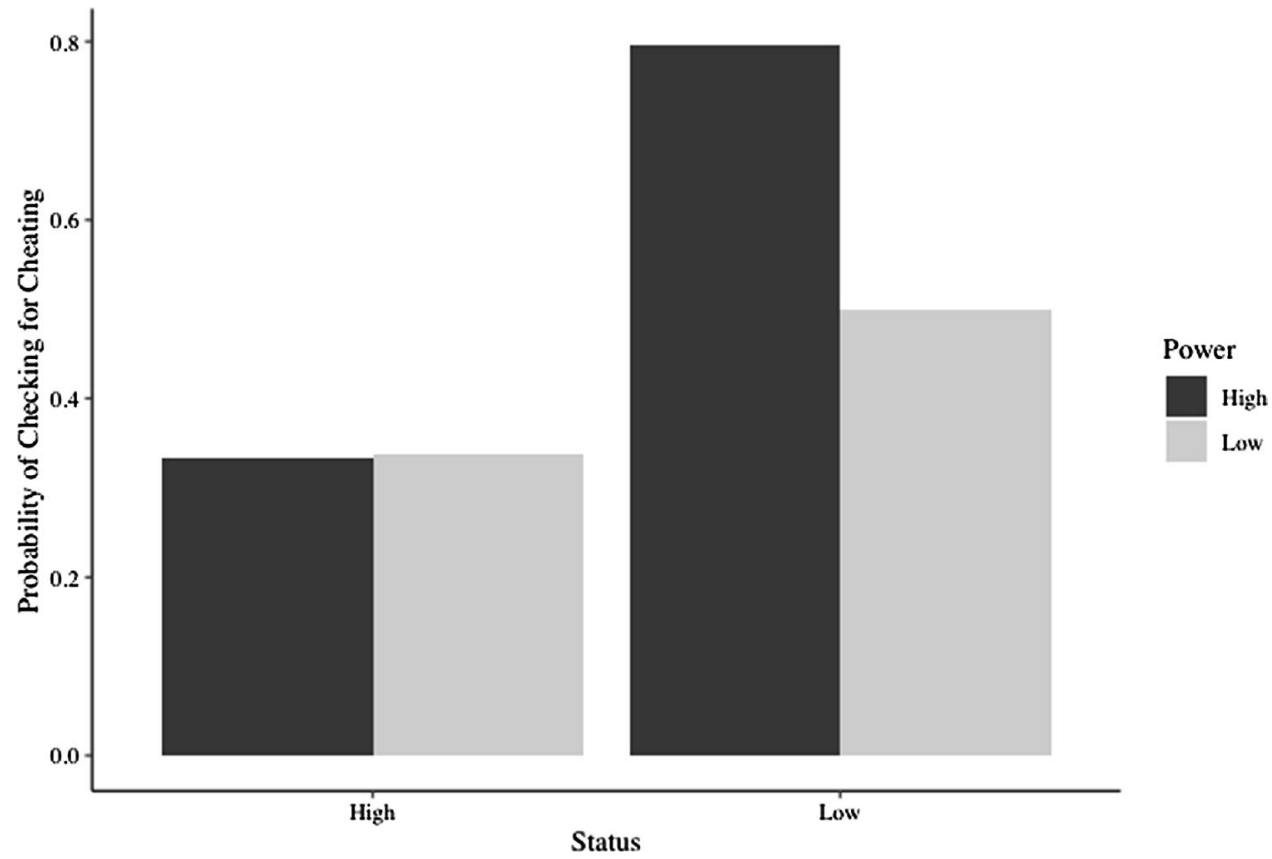

conditions of power and status by estimating a single metaanalytic effect across the studies and.

We computed summary effect sizes for power and status differences in observers' distrust and report the results of a meta-analysis combining data from all four studies with entered means, standard deviations, and sample sizes for the four studies. For all analyses, we obtained effect sizes by calculating the standardized mean differences (Cohen's $d$ ) for the relevant groups (Goh et al., 2016). We conducted both fixed and random effects meta-analyses using the metafor package in R (Viechtbauer, 2010).

\section{Results}

We found that high power-low status targets were trusted less than all power and status combination using both fixed and random effects models. Fixed effects analysis showed that high power-low status targets were trusted less than: low power-low status targets $(\mathrm{H} 1 \mathrm{a} ; \mathrm{d}(95 \% \mathrm{CI})=-0.58(-0.69$, $-0.47), Z=-10.18, p<0.001)$, high status-high power targets $(\mathrm{H} 2 \mathrm{a} ; \mathrm{d}(95 \% \mathrm{CI})=-1.44(-1.57,-1.32), Z=-22.93$, $p<0.001)$ and low power-high status targets (H2c; d(95\% $\mathrm{CI})=-1.35(-1.47,-1.23), Z=-21.43, p<0.001)$.

Random effects analyses revealed similar results. High power-low status targets were trusted less than: low powerlow status $(\mathrm{H} 1 \mathrm{a} ; \mathrm{d}(95 \% \mathrm{CI})=-0.58(-0.69,-0.47)$,

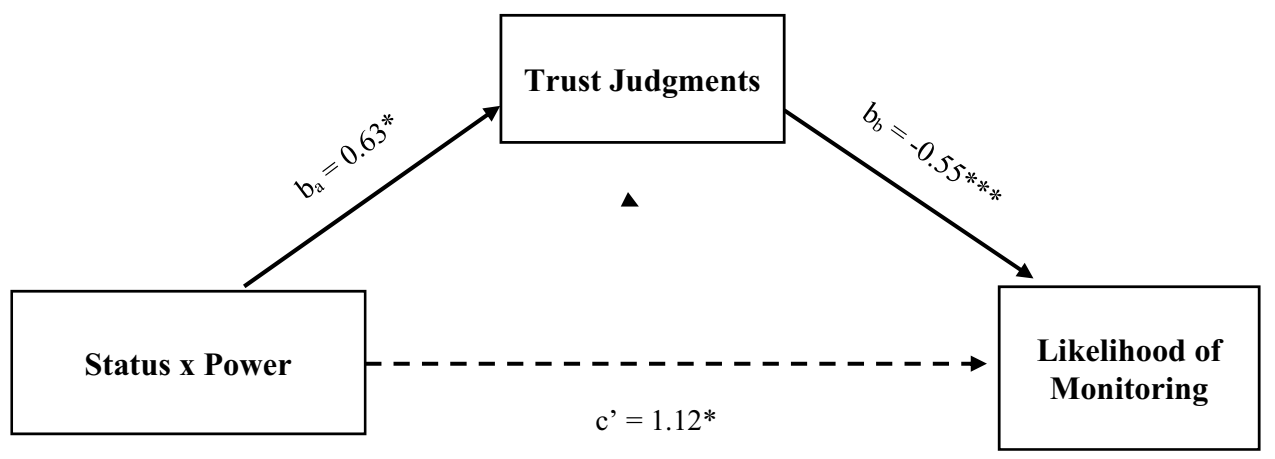

Fig. 7 Mediation analysis (Study 4). Observers' trust judgments partially mediate the interactive effect of the target actor's status and power on the likelihood of being monitored for cheating expressed in log odds (Study 3 ). Unstandardized coefficients $(b)$ are presented; $c^{\prime}$ is the direct effect with the mediator in the model. The indirect effect was significant with 5000 bootstrapped resamples $=0.34$, $S E_{\text {boot }}=0.17,95 \%$ CI $[0.07,0.73] . * p<.05, * * p<.01, * * * p<.001$ 
$Z=-10.18, p<0.001)$, high status-how power targets $(\mathrm{H} 1 \mathrm{~b}$; $\mathrm{d}(95 \% \mathrm{CI})=-1.43(-1.90,-0.97), Z=-6.08, p<0.001)$ and low power-high status targets $(\mathrm{H} 1 \mathrm{c} ; \mathrm{d}(95 \% \mathrm{CI})=-1.34$ $(-1.85,-0.83), Z=-21.43, p<0.001)$.

This internal meta-analysis supports our first hypothesis ( $\mathrm{H} 1 \mathrm{a}, \mathrm{H} 1 \mathrm{~b}$, and $\mathrm{H} 1 \mathrm{c})$ that the structural paradox meaningfully increases observers' distrust as compared to all other conditions of power and status. Further, the results lend support to our hypothesized effect that a violation of expectations between status and power occurs for high power-low status rather than a general incongruency effect between status and power impacting low power-high status.

\section{General Discussion}

The goal of the current research was to deepen our understanding of how the two mechanisms of hierarchical differentiation, power and status, interact to predict observers' distrust of unknown actors. In any hierarchical system, the distribution of status and power involves inequalities between and within parties. That is, actors with access to valued resources (i.e., power) may not have earned a corresponding level of respect and regard from relevant others (i.e., status). While recent research has begun to explore the impact of status on observers' trust (Blue et al., 2019), the combined effect of an actor's level of power and status on observers' distrust and its ethical consequences has remained an open question.

The present set of studies demonstrate that the structural paradox presented, when an actor possesses power without an equivalent level of status (high power-low status), has important implications on observers' depersonalized distrust and ethical monitoring. The results of these studies suggest that the structural paradox of high power accompanied by low status was the stronger predictor of observers' distrust and monitoring behavior. While there were some inconsistencies of specific effects across our studies (Studies 2 and 3), researchers have noted that it is not unusual to find inconsistent patterns of significance across multiple studies (Laken \& Etz, 2017). In order to better estimate the effect of the structural paradox on distrust, we conducted an internal meta-analysis and found reliable evidence of trust differences between the structural paradox and all other conditions of power and status.

Further, tests of indirect effects in Study 3 suggest that observers' distrust is associated with the structural paradox to the extent that observers experience an adverse reaction (i.e., dislike) rather than perceived illegitimacy toward the target's role. Lastly, Study 4 showed that trust judgments carried over into observers' behavior: the effect between the structural paradox and monitoring for cheating was partially mediated by trust judgments.

\section{Theoretical Implications}

The current research makes key contributions to the existing research on distrust and behavioral ethics. First, prior research examining the influence of social hierarchy on trust has primarily focused on the isolated effect of an actor's status on observers' trust. Here, our focus is on observers' depersonalized distrust when a structural paradox exists between the target actor's high power and low status. We draw from the literature that has shown that status and power have distinct consequences on behavior (Blader \& Chen, 2012) and find that status acts as a cue for trust, but its absence alone does not necessarily imply distrust.

Second, we add to current research focused on understanding the factors that affect observers' propensity to (dis) trust others. While the structural paradox signals that when status is low, power over important resources is illegitimate, we find that it is observers' dislike of those with high powerlow status that influences the distrust they experience (Study 3). Indeed, high power-low status targets were not viewed as less legitimate than low power-low status targets, but they were found to be more disliked. Additionally, the results of the internal meta-analysis support our hypothesized effect that a violation of expectations between status and power is consistent with high power-low status rather than a more general conflict between power and status (i.e., low powerhigh status). Together, these findings support our theoretical argument that the structural paradox triggers adverse reactions consistent with violated status expectations responsible for observers' distrust. Indeed, recent work has found that people display aversive reactions (i.e., dislike) to broken expectations of patterns, forms, shapes, and stereotypes (Gollwitzer et al., 2017).

Third, our results broaden our understanding of distrust and monitoring behaviors associated with high power-low status actors. Although recent findings have demonstrated the effects of having high power-low status on one's own behavior (Anicich et al., 2015; Fast et al., 2012), less is known about how perceptions of high power and low status in others influence observers' distrust-related judgments and behavior. Our work demonstrates that power and status positions can "carry over" from one context to another. Even though the power and status relationship between the participant and target actor was not specified, participants used information about the target actor's prior power and status levels to determine their distrust and monitoring behaviors. Further, research on observers' global evaluations and perceptions has mainly focused on the role of moral character in influencing observers' competence judgments, an important element of status judgments (Anderson et al., 2015; 
Goodwin et al., 2014; Stellar \& Willer, 2018). The results of Study 4 add to this research by highlighting how indirect information hinting at an actor's power and status in the observers' context also plays a role in determining observers' moral judgments and monitoring for ethical behavior.

Taken together, these studies yield insights about who is likely to experience distrust based on nothing aside from indirect information about their relative power and status. Our studies demonstrate that low status powerholders experience more distrust and ethical monitoring than actors with any other power-status combination. By focusing on the structural paradox, we contribute to business ethics literature by showing that third-party observers' (dis)trust judgments and behaviors are influenced by social-contextual features which disproportionately impact who is monitored for ethical misconduct.

\section{Future Research and Limitations}

Although the current research specifically examined social status (i.e., status based on respect and regard), an interesting avenue for future research is to explore how the structural paradox combines with other forms of status to influence distrust. For example, status is often ascribed to actors on the basis of demographics, such as gender, race, or age (Berger et al., 1972). To the extent that members of low status groups control valued resources, they may be more distrusted and face increased accusations and monitoring. Indeed, minority leaders have been shown to receive more negative attributions and evaluations than non-minority leaders (e.g., Carton $\&$ Rosette, 2011). Our results seem to indicate that when these cues are inaccurate, observers' expectations deprive an actor of the chance to prove that they may be trustworthy (Fetchenhauer \& Dunning, 2010). From a practical perspective, our studies suggest that when organizations give actors power (i.e., promote them), they would benefit from managing their status or risk the actor being ineffective in their role because of others' distrust. This could be done, for example, by highlighting the actor's value to the group, such as education, past accomplishments, or unique expertise.

Additionally, future research can extend our findings to other types of unethical interpersonal behaviors associated with depersonalized distrust and the structural paradox. For example, incivility, workplace aggression, and unjust punishment may depend on distrusting others.

One potentially interesting finding that was not hypothesized is that status, rather than the structural paradox, accounted for the differences in ability-based (dis)trust judgments. This is consistent with research suggesting that, within organizations, one of the benefits enjoyed by high status individuals is perceived competence (Fiske, 2010; Magee \& Galinsky, 2008). Thus, any conclusions as to whether the structural paradox influences distrust judgments are limited to trust based on benevolence, integrity, and general trust measures. A potential fruitful avenue for future work is to examine the unique effects of the structural paradox on behavioral trust outcomes that may depend on an actor's ability as well as integrity, benevolence, and integrity such as ethics within teams, organizational citizenship behaviors, and performance.

There are aspects of these studies that limit their generalizability. First, participants did not interact with the target actor directly. Face-to-face interactions and ongoing interdependence may influence distrust more than the indirect messages used in these studies. Second, while a strength of laboratory experiments is that they allowed us to establish a causal relationship between the structural paradox and distrust, we recognize that the experimental nature of our studies limit our ability to generalize to organizational settings. Thus, future research can examine whether individuals are more likely to distrust their low status, high power colleagues at work by examining organizational settings.

Third, in Studies 2 and 3, we did not find significant differences in the direct effect for (dis)trust between the structural paradox and the high power-high status condition (Study 3) and the low power-high status condition (Studies 2 and 3). One possibility is that power confounded participants' trust behavior by affecting participants' willingness to send money. That is, once participants choose the initial amount to send, the partner controls the resources and decides how much to send back to the participant. In this case, mediation might explain the relationship between the structural paradox and (dis)trust. When we added a measure of likeability, we found evidence that high power-low status actors were more likely to be distrusted. Further, in Study 4, when targets did not have power over the participants, we found significant differences in monitoring for cheating between the structural paradox and all combinations of status and power. Notably, the internal meta-analysis supported our primary hypothesis that high power-low status targets are trusted less than all other combinations of status and power.

\section{Conclusion}

To conclude, distrust of those with high power-low status can have undesirable consequences particularly because the structural paradox breeds dislike. If power is assigned to actors perceived as having low status, they may not have an equal opportunity for success and/or face targeting for ethical violations. Our findings help understand how the 
combination of high power-low status can shape observers' (dis)trust in depersonalized contexts.

\section{Declarations}

Conflict of interest The authors have no relevant financial, non-financial, and conflict of interest to disclose.

Ethical Approval Approval was obtained from the ethics committee of the University of Virginia and the Technion. The procedures used in this study adhere to the tenets of the Declaration of Helsinki.

Consent to Participate We obtained informed consent from all individual participants included in the studies presented in this paper.

\section{References}

Acquisti, A., Brandimarte, L., \& Loewenstein, G. (2015). Privacy and human behavior in the age of information. Science, 347(6221), 509-514. https://doi.org/10.1126/science.aaa1465

Alasfour, F. (2019). Costs of distrust: The virtuous cycle of tax compliance in Jordan. Journal of Business Ethics, 155(1), 243-258. https://doi.org/10.1007/s10551-017-3473-y

Alder, G. S., Schminke, M., Noel, T. W., \& Kuenzi, M. (2008). Employee reactions to internet monitoring: The moderating role of ethical orientation. Journal of Business Ethics, 80(3), 481-498. https://doi.org/10.1007/s10551-007-9432-2

Alge, B. J., Ballinger, G. A., \& Green, S. G. (2004). Remote control: Predictors of electronic monitoring intensity and secrecy. Personnel Psychology, 57(2), 377-410. https://doi.org/10.1111/j. 1744-6570.2004.tb02495.x

Americans' Trust in Government, Each Other, Leaders. (2019). Pew Research Center - U.S. Politics \&Policy. https://www.pewre search.org/politics/2019/07/22/trust-and-distrust-in-america/

Anderson, C., Hildreth, J. A. D., \& Howland, L. (2015). Is the desire for status a fundamental human motive? A review of the empirical literature. Psychological Bulletin, 141(3), 574-601. https://doi. org/10.1037/a0038781

Anderson, C., John, O. P., Keltner, D., \& Kring, A. M. (2001). Who attains social status? Effects of personality and physical attractiveness in social groups. Journal of Personality and Social Psychology, 81(1), 116-132. https://doi.org/10.1037//0022-3514. 81.1.116

Anderson, C., Kraus, M. W., Galinsky, A. D., \& Keltner, D. (2012). The local-ladder effect: Social status and subjective well-being. Psychological Science, 23(7), 764-771. https://doi.org/10.1177/ 0956797611434537

Anicich, E. M., Fast, N. J., Halevy, N., \& Galinsky, A. D. (2016). How powerful, low-status jobs lead to conflict. Harvard Business Review, February 11.

Anicich, E. M., Fast, N. J., Halevy, N., \& Galinsky, A. D. (2015). When the bases of social hierarchy collide: Power without status drives interpersonal conflict. Organization Science. https://doi.org/10. 1287/orsc. 2015.1019

Ball, K. (2010). Workplace surveillance: An overview. Labor History, 51(1), 87-106. https://doi.org/10.1080/00236561003654776

Balliet, D., Wu, J., \& De Dreu, C. K. W. (2014). Ingroup favoritism in cooperation: A meta-analysis. Psychological Bulletin, 140(6), 1556-1581. https://doi.org/10.1037/a0037737
Berg, J., Dickhaut, J., \& McCabe, K. (1995). Trust, reciprocity, and social history. Games and Economic Behavior, 10(1), 122-142. https://doi.org/10.1006/game.1995.1027

Berger, J., Cohen, B. P., \& Zelditch, M. (1972). Status characteristics and social interaction. American Sociological Review, 37(3), 241-255. https://doi.org/10.2307/2093465

Bernstein, E. S. (2017). Making transparency transparent: The evolution of observation in management theory. Academy of Management Annals, 11(1), 217-266. https://doi.org/10.5465/annals. 2014.0076

Bhave, D. P., Teo, L. H., \& Dalal, R. S. (2020). Privacy at work: A review and a research agenda for a contested terrain. Journal of Management, 46(1), 127-164. https://doi.org/10.1177/01492 06319878254

Bijlsma-Frankema, K., Sitkin, S. B., \& Weibel, A. (2015). Distrust in the balance: The emergence and development of intergroup distrust in a court of law. Organization Science, 26(4), 10181039. https://doi.org/10.1287/orsc.2015.0977

Blader, S. L., \& Chen, Y.-R. (2012). Differentiating the effects of status and power: A justice perspective. Journal of Personality and Social Psychology, 102(5), 994-1014. https://doi.org/10. 1037/a0026651

Blue, P. R., Hu, J., Peng, L., Yu, H., Liu, H., \& Zhou, X. (2019). Whose promises are worth more? How social status affects trust in promises. European Journal of Social Psychology, 00, 1-18. https://doi.org/10.1002/ejsp.2596

Bobko, P., Barelka, A. J., Hirshfield, L. M., \& Lyons, J. B. (2014). Invited Article: The construct of suspicion and how it can benefit theories and models in organizational science. Journal of Business and Psychology, 29(3), 335-342.

Brion, S., Mo, R., Jr., \& Lount, R. B. (2019). Dynamic influences of power on trust: Changes in power affect trust in others. Journal of Trust Research, 9(1), 6-27. https://doi.org/10.1080/21515 581.2018.1552591

Buhrmester, M., Kwang, T., \& Gosling, S. D. (2011). Amazon's mechanical turk: A new source of inexpensive, yet high-quality, data? Perspectives on Psychological Science, 6(1), 3-5. https://doi.org/10.1177/1745691610393980

Carton, A. M., \& Rosette, A. S. (2011). Explaining bias against black leaders: Integrating theory on information processing and goalbased stereotyping. Academy of Management Journal, 54(6), 1141-1158. https://doi.org/10.5465/amj.2009.0745

Chambers, J. R., \& Melnyk, D. (2006). Why Do I hate thee? Conflict misperceptions and intergroup mistrust. Personality and Social Psychology Bulletin, 32(10), 1295-1311. https://doi.org/ 10.1177/0146167206289979

Cheng, J. T., Tracy, J. L., Foulsham, T., Kingstone, A., \& Henrich, J. (2013). Two ways to the top: Evidence that dominance and prestige are distinct yet viable avenues to social rank and influence. Journal of Personality and Social Psychology, 104(1), 103-125. https://doi.org/10.1037/a0030398

Cho, J. (2006). The mechanism of trust and distrust formation and their relational outcomes. Journal of Retailing, 82(1), 25-35. https://doi.org/10.1016/j.jretai.2005.11.002

Colquitt, J. A., Scott, B. A., \& LePine, J. A. (2007). Trust, trustworthiness, and trust propensity: A meta-analytic test of their unique relationships with risk taking and job performance. Journal of Applied Psychology, 92(4), 909-927. https://doi. org/10.1037/0021-9010.92.4.909

Colquitt, J. A., LePine, J. A., Piccolo, R. F., Zapata, C. P., \& Rich, B. L. (2012). Explaining the justice-performance relationship: Trust as exchange deepener or trust as uncertainty reducer? Journal of Applied Psychology, 97(1), 1-15. https://doi.org/10.1037/a0025 208. 
Cook, K., Hardin, R., \& Levi, M. (2005). Cooperation without trust? Russell Sage Foundation. https://doi.org/10.7758/9781610441 353

De Cremer, D., Tenbrunsel, A. E., \& van Dijke, M. (2010). Regulating ethical failures: Insights from psychology. Journal of Business Ethics, 95, 1-6.

Deng, M., Guinote, A., \& Cui, L. (2018). When low power meets status: Powerlessness triggers behavioral inhibition only under low status. Social Cognition, 36(1), 134-166. https://doi.org/ 10.1521/soco.2018.36.1.134

DeSteno, D., Breazeal, C., Frank, R. H., Pizarro, D., Baumann, J., Dickens, L., \& Lee, J. J. (2012). Detecting the trustworthiness of novel partners in economic exchange. Psychological Science, 23(12), 1549-1556. https://doi.org/10.1177/09567 97612448793

Deutsch, M. (1958). Trust and suspicion. The Journal of Conflict Resolution, 2(4), 265-279.

Dunning, D., Anderson, J. E., Schlösser, T., Ehlebracht, D., \& Fetchenhauer, D. (2014). Trust at zero acquaintance: More a matter of respect than expectation of reward. Journal of Personality and Social Psychology, 107(1), 122-141. https://doi.org/10.1037/ a0036673

Etzioni, A. (2019). Cyber trust. Journal of Business Ethics, 156(1), 1-13. https://doi.org/10.1007/s10551-017-3627-y

Fast, N. J., Halevy, N., \& Galinsky, A. D. (2012). The destructive nature of power without status. Journal of Experimental Social Psychology, 48(1), 391-394. https://doi.org/10.1016/j.jesp.2011. 07.013

Faul, F., Erdfelder, E., Lang, A.-G., \& Buchner, A. (2007). G*Power 3: A flexible statistical power analysis program for the social, behavioral, and biomedical sciences. Behavior Research Methods, 39(2), 175-191. https://doi.org/10.3758/BF03193146

Fein, S. (1996). Effects of suspicion on attributional thinking and the correspondence bias. Journal of Personality and Social Psychology, 70(6), 1164-1184. https://doi.org/10.1037/0022-3514.70.6. 1164

Fetchenhauer, D., \& Dunning, D. (2009). Do people trust too much or too little? Journal of Economic Psychology, 30(3), 263-276. https://doi.org/10.1016/j.joep.2008.04.006

Fetchenhauer, D., \& Dunning, D. (2010). Why so cynical?: Asymmetric feedback underlies misguided skepticism regarding the trustworthiness of others. Psychological Science, 21(2), 189-193. https://doi.org/10.1177/0956797609358586

Fiske, S. T. (2010). Interpersonal stratification: Status, power, and subordination. Handbook of social psychology (5th ed., Vol. 2, pp. 941-982). Wiley.

Fiske, S. T., Cuddy, A. J. C., \& Glick, P. (2007). Universal dimensions of social cognition: Warmth and competence. Trends in Cognitive Sciences, 11(2), 77-83. https://doi.org/10.1016/j.tics. 2006.11.005

Fragale, A. R., Overbeck, J. R., \& Neale, M. A. (2011). Resources versus respect: Social judgments based on targets' power and status positions. Journal of Experimental Social Psychology, 47(4), 767-775. https://doi.org/10.1016/j.jesp.2011.03.006

Goh, J. X., Hall, J. A., \& Rosenthal, R. (2016). Mini meta-analysis of your own studies: Some arguments on why and a primer on how. Social and Personality Psychology Compass, 10(10), 535-549. https://doi.org/10.1111/spc3.12267

Gollwitzer, A., Marshall, J., \& Bargh, J. A. (2020). Pattern deviancy aversion predicts prejudice via a dislike of statistical minorities. Journal of Experimental Psychology: General, 149(5), 828-854. https://doi.org/10.1037/xge0000682

Gollwitzer, A., Marshall, J., Wang, Y., \& Bargh, J. A. (2017). Relating pattern deviancy aversion to stigma and prejudice. Nature Human Behaviour, 1(12), 920-927. https://doi.org/10.1038/ s41562-017-0243-X
Goodwin, G. P., Piazza, J., \& Rozin, P. (2014). Moral character predominates in person perception and evaluation. Journal of Personality and Social Psychology, 106(1), 148-168. https://doi. org/10.1037/a0034726

Graso, M., Reynolds, T., \& Grover, S. L. (2020). Allegations of mistreatment in an era of harm avoidance: Taboos, challenges, and implications for management. Academy of Management Perspectives, 34(1), 1-27. https://doi.org/10.5465/amp.2018.0144

Gruenfeld, D., Inesi, E., Magee, J., \& Galinsky, A. (2008). Power and the objectification of social targets. Journal of Personality and Social Psychology, 95, 111-127. https://doi.org/10.1037/00223514.95.1.111

Guinote, A. (2017). How power affects people: Activating, wanting, and goal seeking. Annual Review of Psychology, 68(1), 353-381. https://doi.org/10.1146/annurev-psych-010416-044153

Guinote, A., Willis, G. B., \& Martellotta, C. (2010). Social power increases implicit prejudice. Journal of Experimental Social Psychology, 46(2), 299-307. https://doi.org/10.1016/j.jesp. 2009.11.012

Haesevoets, T., De Cremer, D., De Schutter, L., McGuire, J., Yang, Y., Jian, X., \& Van Hiel, A. (2019). Transparency and control in email communication: The more the supervisor is put in $\mathrm{cc}$ the less trust is felt. Journal of Business Ethics. https://doi.org/ 10.1007/s10551-019-04220-w

Halevy, N., Chou, E., \& Galinsky, A. (2011). A functional model of hierarchy: Why, how, and when vertical differentiation enhances group performance. Organizational Psychology Review, 1, 32-52. https://doi.org/10.1177/2041386610380991

Hayes, A. F. (2017). Introduction to mediation, moderation, and conditional process analysis (2nd ed.). Guilford Publications.

Hays, N. A., \& Blader, S. L. (2017). To give or not to give? Interactive effects of status and legitimacy on generosity. Journal of Personality and Social Psychology, 112(1), 17-38. https://doi. org/10.1037/pspi0000067

Heine, S. J., Proulx, T., \& Vohs, K. D. (2006). The meaning maintenance model: On the coherence of social motivations. Personality and Social Psychology Review, 10(2), 88-110.

Huo, Y. J., Binning, K. R., \& Molina, L. E. (2010). Testing an integrative model of respect: Implications for social engagement and well-being. Personality and Social Psychology Bulletin, 36(2), 200-212. https://doi.org/10.1177/0146167209356787

Islam, G. (2020). Psychology and business ethics: A multi-level research agenda. Journal of Business Ethics, 165(1), 1-13. https://doi.org/10.1007/s10551-019-04107-w

Keltner, D., Gruenfeld, D. H., \& Anderson, C. (2003). Power, approach, and inhibition. Psychological Review, 110(2), 265-284. https:// doi.org/10.1037/0033-295X.110.2.265

Kennedy, J. A., \& Schweitzer, M. E. (2018). Building trust by tearing others down: When accusing others of unethical behavior engenders trust. Organizational Behavior and Human Decision Processes, 149, 111-128. https://doi.org/10.1016/j.obhdp.2018. 10.001

Kramer, R. M. (1999). TRUST AND DISTRUST IN ORGANIZATIONS: Emerging perspectives, enduring questions. Annual Review of Psychology, 50(1), 569-598. https://doi.org/10.1146/ annurev.psych.50.1.569

Kunstman, J. W., \& Maner, J. K. (2011). Sexual overperception: Power, mating motives, and biases in social judgment. Journal of Personality and Social Psychology, 100(2), 282-294. https://doi. org/10.1037/a0021135

Lakens, D., \& Etz, A. J. (2017). Too true to be bad: When sets of studies with significant and nonsignificant findings are probably true. Social Psychological and Personality Science, 8(8), 875-881. https://doi.org/10.1177/1948550617693058 
Langfred, C. W. (2004). Too much of a good thing? Negative effects of high trust and individual autonomy in self-managing teams. Academy of Management Journal, 16, 385-399.

Langfred, C. W., \& Rockmann, K. W. (2016). The push and pull of autonomy: The tension between individual autonomy and organizational control in knowledge work. Group \& Organization Management, 41(5), 629-657. https://doi.org/10.1177/1059601116 668971

Levine, L. (2019). Digital trust and cooperation with an integrative digital social contract. Journal of Business Ethics, 160(2), 393-407. https://doi.org/10.1007/s10551-019-04201-z

Levy, K. E. C. (2015). The contexts of control: Information, power, and truck-driving work. The Information Society, 31(2), 160-174. https://doi.org/10.1080/01972243.2015.998105

Lewicki, R. J., McAllister, D. J., \& Bies, R. J. (1998). Trust and distrust: New relationships and realities. The Academy of Management Review, 23(3), 438-458. https://doi.org/10.2307/259288

Long, C. P., \& Sitkin, S. B. (2018). Control-trust dynamics in organizations: Identifying shared perspectives and charting conceptual fault lines. Academy of Management Annals, 12(2), 725-751. https://doi.org/10.5465/annals.2016.0055

Lount, R. B., \& Pettit, N. C. (2012). The social context of trust: The role of status. Organizational Behavior and Human Decision Processes, 117(1), 15-23. https://doi.org/10.1016/j.obhdp.2011. 07.005

Magee, J. C., \& Galinsky, A. D. (2008). Social hierarchy: The selfreinforcing nature of power and status. The Academy of Management Annals, 2(1), 351-398. https://doi.org/10.1080/19416 520802211628

Mannix, E. A., \& Sauer, S. J. (2006). Status and power in organizational group research: Acknowledging the pervasiveness of hierarchy. In R. T. Shane \& J. L. Edward (Eds.), Advances in group processes (pp. 149-182). Emerald. https://doi.org/10.1016/ S0882-6145(06)23006-6

Martin, K., \& Freeman, R. E. (2003). Some problems with employee monitoring. Journal of Business Ethics, 43(4), 353-361. https:// doi.org/10.1023/A:1023014112461

Massey, K., Freeman, S., \& Zelditch, M. (1997). Status, power, and accounts. Social Psychology Quarterly, 60(3), 238-251. https:// doi.org/10.2307/2787084

Mayer, R. C., \& Davis, J. H. (1999). The effect of the performance appraisal system on trust for management: A field quasi-experiment. Journal of Applied Psychology, 84(1), 123-136. https:// doi.org/10.1037/0021-9010.84.1.123

Mayer, R. C., Davis, J. H., \& Schoorman, F. D. (1995). An integrative model of organizational trust. Academy of Management Review, 20(3), 709-734. https://doi.org/10.5465/AMR.1995.9508080335

Mooijman, M., van Dijk, W. W., van Dijk, E., \& Ellemers, N. (2019). Leader power, power stability, and interpersonal trust. Organizational Behavior and Human Decision Processes, 152, 1-10. https://doi.org/10.1016/j.obhdp.2019.03.009

Naquin, C. E., Kurtzberg, T. R., \& Belkin, L. Y. (2010). The finer points of lying online: E-mail versus pen and paper. Journal of Applied Psychology, 95(2), 387-394. https://doi.org/10.1037/ a0018627

Overbeck, J. R., Correll, J., \& Park, B. (2005). Internal status sorting in groups: The problem of too many stars. Research on managing groups and teams (Vol. 7, pp. 169-199). Emerald. https://doi.org/ 10.1016/S1534-0856(05)07008-8

Paolacci, G., \& Chandler, J. (2014). Inside the Turk: Understanding mechanical Turk as a participant pool. Current Directions in Psychological Science, 23(3), 184-188. https://doi.org/10.1177/ 0963721414531598

Pillutla, M. M., Malhotra, D., \& Keith Murnighan, J. (2003). Attributions of trust and the calculus of reciprocity. Journal of
Experimental Social Psychology, 39(5), 448-455. https://doi. org/10.1016/S0022-1031(03)00015-5

Proulx, T., \& Heine, S. J. (2010). The Frog in Kierkegaard's beer: Finding meaning in the threat-compensation literature: Meaning and threat-compensation. Social and Personality Psychology Compass, 4(10), 889-905. https://doi.org/10.1111/j.1751-9004. 2010.00304.x

Proulx, T., Inzlicht, M., \& Harmon-Jones, E. (2012). Understanding all inconsistency compensation as a palliative response to violated expectations. Trends in Cognitive Sciences, 16(5), 285-291. https://doi.org/10.1016/j.tics.2012.04.002

Righetti, F., \& Finkenauer, C. (2011). If you are able to control yourself, I will trust you: The role of perceived self-control in interpersonal trust. Journal of Personality and Social Psychology, 100(5), 874-886. https://doi.org/10.1037/a0021827

Rousseau, D. M., Sitkin, S. B., Burt, R. S., \& Camerer, C. (1998). Introduction to special topic forum: Not so different after all: A cross-discipline view of trust. The Academy of Management Review, 23(3), 393-404.

Saunders, M. N., Dietz, G., \& Thornhill, A. (2014). Trust and distrust: Polar opposites, or independent but co-existing? Human Relations, 67(6), 639-665. https://doi.org/10.1177/0018726713 500831

Schilke, O., \& Huang, L. (2018). Worthy of swift trust? How brief interpersonal contact affects trust accuracy. Journal of Applied Psychology, 103(11), 1181-1197. https://doi.org/10.1037/ap100 00321

Schilke, O., Reimann, M., \& Cook, K. S. (2015). Power decreases trust in social exchange. Proceedings of the National Academy of Sciences of the United States of America, 112(42), 12950-12955.

Schoorman, F. D., Mayer, R. C., \& Davis, J. H. (2007). An integrative model of organizational trust: Past, present, and future. Academy of Management Review, 32(2), 344-354. https://doi.org/10.5465/ AMR.2007.24348410

Schul, Y., Mayo, R., \& Burnstein, E. (2008). The value of distrust. Journal of Experimental Social Psychology, 44(5), 1293-1302. https://doi.org/10.1016/j.jesp.2008.05.003

Schweitzer, M. E., Ho, T.-H., \& Zhang, X. (2018). How monitoring influences trust: A tale of two faces. Management Science, 64(1), 253-270. https://doi.org/10.1287/mnsc.2016.2586

Sinaceur, M. (2010). Suspending judgment to create value: Suspicion and trust in negotiation. Journal of Experimental Social Psychology, 46(3), 543-550. https://doi.org/10.1016/j.jesp.2009.11.002

Stellar, J. E., \& Willer, R. (2018). Unethical and inept? The influence of moral information on perceptions of competence. Journal of Personality and Social Psychology, 114(2), 195-210. https://doi. org/10.1037/pspa0000097

Stolle, D. (2002). Trusting strangers: The concept of generalized trust in perspective. Osterreichische Zeitschrift Für Politikwissenschaft, 4, 397-412.

Tanis, M., \& Postmes, T. (2005). A social identity approach to trust: Interpersonal perception, group membership and trusting behaviour. European Journal of Social Psychology, 35(3), 413-424. https://doi.org/10.1002/ejsp.256

Thompson, L. F., Sebastianelli, J. D., \& Murray, N. P. (2009). Monitoring online training behaviors: Awareness of electronic surveillance hinders e-learners. Journal of Applied Social Psychology, 39(9), 2191-2212. https://doi.org/10.1111/j.1559-1816.2009. 00521.x

Tinsley, C. H., O’Connor, K. M., \& Sullivan, B. A. (2002). Tough guys finish last: The perils of a distributive reputation. Organizational Behavior and Human Decision Processes, 88(2), 621-642. https://doi.org/10.1016/S0749-5978(02)00005-5

Treviño, L. K., den Nieuwenboer, N. A., \& Kish-Gephart, J. J. (2014). (Un)ethical behavior in organizations. Annual Review 
of Psychology, 65(1), 635-660. https://doi.org/10.1146/annur ev-psych-113011-143745

Tyler, T. R. (2006). Psychological perspectives on legitimacy and legitimation. Annual Review of Psychology, 57(1), 375-400. https:// doi.org/10.1146/annurev.psych.57.102904.190038

Tyler, T. R., Goff, P. A., \& MacCoun, R. J. (2015). The impact of psychological science on policing in the United States: Procedural justice, legitimacy, and effective law enforcement. Psychological Science in the Public Interest, 16(3), 75-109. https://doi.org/10. $1177 / 1529100615617791$

van der Toorn, J., Tyler, T. R., \& Jost, J. T. (2011). More than fair: Outcome dependence, system justification, and the perceived legitimacy of authority figures. Journal of Experimental Social Psychology, 47(1), 127-138. https://doi.org/10.1016/j.jesp.2010. 09.003

van Kleef, G. A., Oveis, C., van der Löwe, I., LuoKogan, A., Goetz, J., \& Keltner, D. (2008). Power, distress, and compassion: Turning a blind eye to the suffering of others. Psychological Science, 19(12), 1315-1322. https://doi.org/10.1111/j.1467-9280.2008. 02241.x

Viechtbauer, W. (2010). Conducting meta-analyses in R with the metafor Package. Journal of Statistical Software, 36(1), 1-48. https:// doi.org/10.18637/jss.v036.i03
Vohs, K. D., \& Schooler, J. W. (2008). The value of believing in free will: Encouraging a belief in determinism increases cheating. Psychological Science, 19(1), 49-54.

Willis, J., \& Todorov, A. (2006). First impressions: Making up your mind after a $100-$ Ms exposure to a face. Psychological Science, 17(7), 592-598. https://doi.org/10.1111/j.1467-9280.2006. 01750.x

Zand, D. E. (1972). Trust and managerial problem solving. Administrative Science Quarterly, 17(2), 229-239. https://doi.org/10. $2307 / 2393957$

Zlatev, J. J. (2019). I may not agree with you, but I trust you: Caring about social issues signals integrity. Psychological Science, 30(6), 880-892. https://doi.org/10.1177/0956797619837948

Publisher's Note Springer Nature remains neutral with regard to jurisdictional claims in published maps and institutional affiliations. 